\title{
Los exiliados económicos. La tercera oleada de emigración española a Chile (2008-2014) ${ }^{1}$
}

\author{
María Jara Rodríguez-Fariñas², Juan Manuel Romero-Valiente ${ }^{3}$ \\ y Antonio Luis Hidalgo-Capitán ${ }^{4}$
}

\begin{abstract}
RESUMEN
El artículo analiza la emigración española a Chile entre 2008 y 2014, con los objetivos de definir el perfil del nuevo emigrante español a Chile, conocer las causas de su emigración, detectar los problemas iniciales de su proceso migratorio, identificar su situación actual y conocer sus expectativas de futuro. Se ha utilizado una estrategia metodológica mixta, cuantitativa y cualitativa, combinando investigación de primer y segundo orden. Se concluye que estos emigrantes son jóvenes altamente cualificados, expulsados de España por la crisis y atraídos a Chile por las oportunidades de adquirir experiencia laboral, que han encontrado una red migratoria formada por otros españoles y que están ocupando empleos cualificados que la mano de obra nacional no puede ocupar en los sectores de minería y energía; no han encontrado dificultades en su proceso migratorio, se encuentran satisfechos con su experiencia y entre sus expectativas predomina la idea de quedarse en Chile o reemigrar.
\end{abstract}

Palabras clave: España; Chile; emigración; profesionales; crisis.

\begin{abstract}
The article analyzes Spanish emigration to Chile between 2008 and 2014, with the aim of defining the profile of new Spanish emigrants to Chile, understanding the reasons for their migration, identifying initial problems in the migration process, identifying the conditions of their current situation and understanding their future expectations. We used a mixed quantitative and qualitative methodological strategy, combining first and second order research. We have concluded that these emigrants are highly skilled young people, expelled from Spain by the crisis and attracted to Chile by the opportunities to gain work experience; in Chile they encounter a migratory network of Spanish emigrants who hold qualified jobs that the national population could not fill in the mining and energy sectors; they have not encountered any particular difficulties in their migration process, are satisfied with their experiences and their expectations for the future include staying in Chile or re-emigrating
\end{abstract}

Key words: Spain; Chile; emigration; professionals, crisis.

\footnotetext{
1 Esta investigación forma parte del proyecto de investigación "Movilidad Humana", que se enmarca dentro del Proyecto de Cooperación Interuniversitaria entre la Universidad de Huelva (España) y la Universidad de Cuenca (Ecuador) para el "Fortalecimiento institucional de la Universidad de Cuenca en materia de buen vivir y movilidad humana" (Proyecto FIUCUHU) financiado por la Agencia Andaluza de Cooperación Internacional para el Desarrollo. Ar-
}

tículo recibido el 7 de octubre de 2014, aceptado el 29 de enero de 2015 y corregido el 20 de febrero de 2015.

2 Unidad de Investigación en Población y Desarrollo local (PYDLOS), Universidad de Cuenca (Ecuador). E-mail: mariajara.rodriguez@alu.uhu.es

3 Centro de Investigación en Migraciones, Universidad de Huelva (España). E-mail: valiente@uhu.es

4 FLACSO-España (España).E-mail: alhc@uhu.es 
En unos momentos en los que vuelven a llegar a Chile emigrantes españoles cobran vigencia los versos de Neruda (1939: Himno y regreso): "Patria, mi patria, vuelvo hacia ti la sangre (...). Acoge esta guitarra ciega y esta frente perdida. Salí a encontrarte hijos por la tierra, salí a cuidar caídos con tu nombre de nieve, salí a hacer una casa con tu madera pura, salí a llevar tu estrella a los héroes heridos". Y es que España ha sido un país de emigrantes durante la mayor parte de su historia, al igual que Chile lo ha sido de inmigrantes.

La emigración española al exterior ha sido prácticamente constante desde el descubrimiento de América hasta mediados de los años setenta del siglo XX. A partir de ese momento, muchos de los emigrantes españoles retornaron atraídos por el fin de la dictadura y empujados por el impacto de la crisis económica internacional en los países de destino; y hacia finales de los años ochenta, como consecuencia del fuerte crecimiento de su economía, España pasó a convertirse en un país de inmigrantes (Bover \& Velilla, 1999). El crecimiento económico español entre 1985 y 2007 permitió que los inmigrantes ocuparan unos nichos laborales abandonados por una parte de la población española, que prefería formarse para ocupar puestos más cualificados. Así, tras el estallido de la crisis económica global en 2008, estos españoles con amplia formación (especialmente universitarios) no han encontrado en España las oportunidades laborales con las que habían soñado y ello ha generado la emigración al exterior de miles de ellos entre 2008 y $2014^{5}$.

La nueva emigración española es, por tanto, un fenómeno relativamente reciente y poco estudiado de manera global, más allá del debate sobre su dimensión (GonzálezFerrer, 2013; González-Enríquez, 2013 ). Aunque existen algunos estudios parciales de dicho fenómeno, bien por países de destino,

\footnotetext{
5 Las cifras de los nuevos emigrantes españoles (2008-2012) varían según las fuentes oficiales y los diferentes analistas que han trabajado sobre el tema, y van desde unos 40.000 emigrantes -entre 2009 y 2012- (González-Enríquez, 2013), a unos 220.000 (INE-E, 2014c) e incluso a unos 700.000 (GonzálezFerrer, 2013).
}

bien por colectivos de emigrantes (Mendoza y Ortiz, 2006 y 2008; Morgan, 2008; Massanet, 2010; Alaminos y Santacreu, 2010; Alaminos et al., 2010; González-Enríquez, 2012; Alcalde et al., 2013; Romero-Valiente, 2013; Rodríguez-Fariñas et al., 2015), el único estudio global hasta la fecha es un informe inédito elaborado para la Dirección General de Migraciones del Gobierno de España bajo el título "La movilidad exterior de los españoles y las españolas en la actualidad" (RomeroValiente, 2012).

El Instituto Nacional de Estadística de España (INE-E), por medio de la Estadística de Variaciones Residenciales (EVR) ${ }^{6}$, estima que entre 2008 y 2013 se produjeron 288.785 emigraciones de españoles al extranjero, de las cuales 120.036 fueron al continente americano; y entre los países americanos de destino Chile ocupa el séptimo puesto, tras Brasil, Colombia, Venezuela, Argentina, Ecuador y Estados Unidos, con 5.270 emigraciones de españoles (INE-E, 2014c). Por otra parte, la colonia española en Chile ha sido tradicionalmente, y es en la actualidad, una de las más importantes entre las foráneas que residen en este país. Según los datos del Censo de Población de 2012 algo más de 11.000 personas nacidas en España residen en Chile (INE-C, 2013). Ello convierte a la colonia española en la sexta por número de integrantes (tras Ecuador, Bolivia, Colombia, Argentina y Perú) y en la primera de entre las integradas por personas que proceden de fuera del ámbito sudamericano. Además desde el año 2008, y

\footnotetext{
6 Para dimensionar y conocer el perfil demográfico de la reciente emigración española a Chile, en este trabajo se ha optado por utilizar principalmente los datos tipo flujo de carácter anual de la "Estadística de Variaciones Residenciales" (INE-E, 2014c) y de la "Estadística de Migraciones" (INE-E, 2014b) por ser, a nuestro juicio, los que permiten una mejor aproximación a este fenómeno. Cabe reseñar, en todo caso, que en este trabajo también han sido tenidos en cuenta los datos del "Padrón de Españoles Residentes en el Extranjero" (PERE) (INE-E, 2014d) y del "Censo de Población y Vivienda 2012" de Chile (Instituto Nacional de Estadísticas de Chile, INE-C, 2013). No obstante, el hecho de que ambas fuentes recojan datos de stock, que incluyen también a personas emigradas a Chile en años y períodos precedentes, las limita un poco para el análisis de un fenómeno tan dinámico. Además, en el caso del Censo de Población de Chile de 2012, cabe indicar que sus resultados están siendo muy cuestionados.
} 
principalmente a partir del 2010, la llegada de españoles a Chile está siendo constante.

$\mathrm{Y}$ aunque hay interesantes investigaciones sobre el periodo de colonización (Bengoa, 1992), sobre las migraciones de industriales españoles (Navarro y Estrada, 2005) o el exilio republicano en Chile (Lemus, 2002), la bibliografía sobre esta nueva emigración de españoles a Chile es, como poco, escasa; de ahí su interés por el estudio.

El propósito de esta investigación es estudiar las características de la nueva emigración española a Chile derivada de la crisis económica entre 2008 y 2014. Para ello nos plantearemos las siguientes preguntas: ¿cuál es el perfil sociodemográfico de los españoles emigrados a Chile desde 2008 a la actualidad?; ¿cuáles son las causas de la nueva emigración de españoles a Chile?; ¿cuáles fueron las dificultades iniciales en su proceso migratorio?; ¿cuál es su situación actual?; y ¿cuáles son sus expectativas de futuro?

Así pues, los objetivos de esta investigación serán definir el perfil del nuevo emigrante español a Chile, conocer las causas de su emigración, detectar los problemas iniciales de su proceso migratorio, identificar las condiciones de su situación actual y conocer sus expectativas de futuro.

Para abordar este tipo de análisis utilizaremos una estrategia metodológica de tipología mixta en la que se emplearán tanto técnicas cuantitativas como cualitativas, combinando la investigación de primer orden (con la utilización de datos objetivos) y de segundo orden (con la captación de percepciones de los sujetos) (Hernández-Sampieri et al., 2006). Además, en el análisis de los resultados se tomarán en consideración variables de muy diversa naturaleza (históricas, demográficas, geográficas, económicas, sociológicas, políticas, culturales, jurídicas...) y marcos teóricos procedentes de diferentes disciplinas.

\section{Métodos y fuentes}

El estudio se basa en un análisis mixto cualitativo y cuantitativo a partir de datos estadísticos elaborados por organismos oficiales internacionales, españoles y chilenos, de en- trevistas extensas y entrevistas online autoadministradas realizadas a españoles residentes en Chile.

Los datos estadísticos españoles proceden del Instituto Nacional de Estadística de España (INE-E); en especial de la Estadística de Variaciones Residenciales (EVR), de la Estadística de Migraciones, del Padrón de Españoles Residentes en el Extranjero (PERE), del Padrón Municipal, de la Encuesta Anual de Estructura Salarial y de la Encuesta de Población Activa (EPA); también se han utilizado datos del Instituto de Comercio Exterior (ICEX). Mientras que los datos estadísticos chilenos lo hacen del Instituto Nacional de Estadística de Chile (INE-C); en especial del Censo de Población y Vivienda de 2012, de la Encuesta Nacional de Empleo, de la Nueva Encuesta Suplementaria de Ingresos; también se han utilizado datos del Banco Central de Chile (BCC), de la Dirección del Trabajo del Gobierno de Chile, del Ministerio de Educación de Chile, de la Fundación Chile (fundación públicoprivada) y de la Cámara Hispano-Chilena. Por lo que se refiere a los datos estadísticos de organismos internacionales, estos proceden del Programa de la Naciones Unidas para el Desarrollo (PNUD), de la Organización para la Cooperación y el Desarrollo Económico (OCDE), de la Comisión Económica para América Latina y el Caribe (CEPAL), del Centro Latinoamericano de Desarrollo (CELADE) y de la Comisión Europea.

Respecto de las entrevistas extensas, se mantuvieron dos videoconferencias, mediante la aplicación Skype, con informantes claves residentes en Chile: un emigrante español con beca de estudios y un emigrante español vinculado con asociaciones de españoles.

Respecto de las entrevistas online autoadministradas se realizaron $110^{7}$, siguiendo un muestreo no probabilístico de bola de nieve virtual, ante la imposibilidad de realizar un

\footnotetext{
7 En realidad fueron 114 entrevistas, pero se excluyeron del análisis cuantitativo y cualitativo las realizadas a tres españoles residentes en Chile antes de 2008 y la realizada a un español nacido en el extranjero; aunque la información procedente de las mismas se ha utilizado para contextualizar el fenómeno objeto de estudio.
} 
muestreo probabilístico por encontrarnos ante una población oculta; entendiendo por población oculta aquella cuyo tamaño es relativamente bajo, sus miembros son difíciles de identificar, el marco muestral es inexistente o incompleto y se desconoce la distribución geográfica de la misma (Marpsata \& Razafindratsimab, 2010: 4). En nuestro caso se desconoce el número de españoles nacidos en España, mayores de edad, residentes en Chile y emigrados entre 2008 y 2014, aunque no parece que la población objeto de estudio pudiera llegar a la cantidad de 6.000 personas; lo cual significa que nos encontramos ante una población relativamente pequeña, frente a los casi 17 millones de habitantes de Chile, muy dispersa por los casi 800.000 $\mathrm{km}^{2}$ del país y parte de ella no registrada. Los datos procedentes de estas entrevistas no poseen, por tanto, representatividad estadística, aunque sí buen nivel de validez externa (Brickman-Bhutta, 2012; Baltar y Gorjup, 2012), y han de ser considerados como aproximaciones válidas a las diferentes dimensiones cuantitativas y cualitativas del fenómeno migratorio ${ }^{8}$.

Para ello se elaboró un cuestionario con 50 preguntas abiertas, semiabiertas y cerradas, utilizando la aplicación Google Docs, que sirvió para alojar dicho cuestionario, gestionar su cumplimentación y recopilar los datos. Los entrevistados fueron reclutados a partir de un enlace, remitido por correo electrónico a algunas personas localizadas previamente y colocado en diferentes espacios de Internet relacionados con las comunidades de españoles residentes en Chile (grupos de la red social Facebook y websites como Spaniards.es o Nonosvamosnosechan.net).

Las preguntas del cuestionario se pueden clasificar en cinco bloques: datos personales para el estudio sociodemográfico; causas de la emigración a Chile; dificultades relacionadas con el proceso migratorio; situación laboral y social en Chile y nivel de satisfac-

\footnotetext{
8 Somos conscientes de que este método de muestreo da como resultado una sobrerrepresentación de la población más joven, que es la que utiliza mayoritariamente las nuevas tecnologías de la información y las telecomunicaciones. De hecho un poco más del $90 \%$ de los entrevistados tiene entre 23 y 44 años.
}

ción; y expectativas de futuro y posibilidad de retorno.

Toda esta información empírica ha sido además relacionada con diferentes informes y estudios procedentes de organismos públicos y privados internacionales (OCDE; CEPAL; Comisión Europea, Banco Mundial, Mercer Consulting), chilenos (INE-C; Ministerio de Educación de Chile; MTPS) y españoles (INE-E; Ministerio de Asuntos Exteriores y de Cooperación, MAEC; Ministerio de Empleo y Seguridad Social, MESS; Fundación Alternativa), así como trabajos académicos y noticias de prensa.

\section{Las migraciones norte-sur}

Tradicionalmente, el estudio sobre las migraciones internacionales y su impacto sobre el desarrollo se ha centrado en las migraciones sur-norte. $Y$ aunque en los últimos años ha crecido el interés por el estudio de las migraciones sur-sur, no ocurre lo mismo respecto de las migraciones norte-sur, por lo que se trata de un campo de estudio poco desarrollado.

Estas migraciones representan, a lo sumo, en torno al $6 \%$ del total de los flujos migratorios mundiales, y se han mantenido más o menos constantes en unos 13 millones de migrantes al año entre 1990 y 2010. Y aunque todo apunta a que, en los últimos años, las mismas han crecido como consecuencia de la crisis económica global, que ha tenido mayor impacto en el norte, las estadísticas internacionales aún no recogen su impacto (OIM, 2013: 79).

La mayor parte de dichos flujos norte-sur se corresponden con migraciones de retorno, es decir, con flujos de regreso a sus países de origen en el sur de aquellos inmigrantes residentes en países del norte (Laczko \& Brian, 2013). Dichos flujos han sido relativamente constantes en las últimas décadas, sin embargo, en los últimos años se aprecia un incremento que parece estar relacionado con el impacto de la crisis económica sobre la situación laboral de dichos inmigrantes (OIM, 2013: 82).

No obstante, entre los emigrantes nortesur también hay personas nacidas en países 
del norte con diferentes perfiles. El primero de ellos es el de los hijos y cónyuges de los emigrantes retornados nacidos en el norte, cuya motivación es el mantenimiento de la unidad familiar ahora en el sur; lógicamente, las migraciones de estos suelen ser más numerosas entre países que mantienen importantes flujos de retorno.

El segundo perfil, y el que se estima que más ha crecido en los últimos años, es el de los trabajadores cualificados del norte que emigran a los países del sur de forma independiente, en especial hacia las denominadas economías emergentes, en busca de las oportunidades laborales que no existen allí como consecuencia de la crisis económica (Docquier \& Lodigiani, 2010). A ellos hay que unir los emigrantes que responden a un tercer perfil, el de los expatriados (Brazier, 2012), es decir, el de los trabajadores cualificados del norte (incluso inmigrantes procedentes del sur) que son empleados por empresas transnacionales con casa matriz en países del norte y que son desplazados a países del sur por dichas empresas por periodos largos de tiempo; en este caso, los países de destino no son solo las economías emergentes, sino también otros países del sur donde existen oportunidades de negocio (como es el caso de los países con abundancia de recursos mineros) (OIM, 2013: 81). En ambos casos, los emigrantes cualificados del norte pueden llegar a ocupar puestos de responsabilidad, pueden tener oportunidades de promoción laboral y pueden disfrutar de unas condiciones económicas que suelen estar por encima de la media del país del sur al que emigran. A ellos hay que unir un quinto perfil, el de los cooperantes internacionales (religiosos, misioneros y miembros de ONGs) procedentes de países del norte que residen largos periodos de tiempo en países del sur.

Junto a estos hay dos perfiles más de emigrantes que no forman parte de la población activa; se trata de los jubilados y los estudiantes (Mattoo \& Subramanian, 2013). Algunos jubilados de países del norte deciden retirarse y vivir en países del sur donde normalmente el poder adquisitivo de sus pensiones es mayor y donde el clima suele ser más cálido (OIM, 2013: 84); mientras que algunos estudiantes del norte deciden continuar sus estudios de grado y, sobre todo, de posgrado en países del sur, aprovechando diferentes programas de becas internacionales (OIM, 2013: 83).

Las corrientes migratorias norte-sur a pesar de su escaso peso relativo pueden tener importantes repercusiones en el desarrollo de los países receptores (OIM, 2013: 85). De hecho aportan tanto capital humano como capital financiero, contribuyen invertir la tendencia del éxodo intelectual sur-norte y, en el caso de los migrantes no activos (estudiantes y jubilados) contribuyen al estímulo de la demanda agregada por la vía del consumo (vivienda, alimentación, vestido, ocio, turismo...) (Dixon et al., 2006).

Las migraciones entre España y Chile se inscriben en este marco de referencia. Y ello es así en la medida en que España es un país del norte duramente sacudido por la crisis económica global, mientras que Chile suele ser considerado como uno de los países emergentes del sur, donde hay muchas oportunidades laborales para trabajadores cualificados, en especial en el sector de la minería, y tanto en empresas transnacionales con casa matriz en España como en otras empresas extranjeras y nacionales; además de ser un gran receptor de estudiantes de posgrado por el alto nivel formativo de algunas de sus universidades. La emigración de españoles a Chile formaría parte de esta nueva emigración de norte-sur, en especial de la llamada nueva emigración española (Romero-Valiente, 2012 y 2013; Rodríguez-Fariñas et al., 2015), en la que el perfil predominante suele ser el de jóvenes altamente cualificados que encuentran en países del sur (Chile, México, Ecuador, Perú, China, Emiratos Árabes Unidos...) y del norte (Reino Unido, Alemania, Francia, Estados Unidos...) las oportunidades que su país no les ofrece.

\section{Los flujos migratorios de España a Chile en perspectiva histórica}

Las migraciones de los españoles a Chile, al margen de las producidas a la Gobernación y luego Capitanía General de Chile durante la época colonial (y que fueron muy escasas en comparación con otros territorios coloniales españoles) (Vázquez y Amores, 
1991: 139), comenzaron a ser significativas a partir 1880. Entre 1880 y 1907 Chile experimentó una importante llegada de emigrantes españoles, que podría estimarse en unas 20.000 personas $^{9}$ y a la que podríamos denominar como "la primera oleada de $\operatorname{coños}^{\prime 10}$. Dicha oleada migratoria vino impulsada por el propio gobierno chileno con la intención de poblar de colonos las regiones del sur del país, aunque la mayoría de los emigrantes españoles terminaron dedicados a actividades comerciales (panaderías, confiterías, bodegas de vinos y licores, joyerías, almacenes, hoteles...) e industriales (fábricas textiles -Gual y Cía-, de espejos -San Bernardo-, de productos químicos...) y residiendo en Santiago y Valparaíso (Aranda, 1929; Estrada, 2012: 2) donde las colonias de españoles descendientes de los españoles residentes en Chile durante el periodo colonial les prestaron un importante apoyo.

Posteriormente, entre 1939 y 1942, Chile vivió otra importante llegada de emigrantes españoles, cifrada en unas 3.500 personas (Lemus, 1998: 273-293) y a la que podríamos denominar como "la segunda oleada de coños". Bajo el liderazgo del poeta Pablo Neruda, delegado para la inmigración española del gobierno chileno, se fletó un barco desde Francia en 1939 con 2.200 "exiliados políticos" españoles, al que seguirían otros barcos con grupos más reducidos, además de exiliados españoles llegados por tierra desde Argentina (Estrada, 2009: 112). A pesar de que oficialmente Chile solo admitía a trabajadores manuales del campo, de la mar, de la industria y de la construcción, considerados necesarios para el desarrollo del país (De Llera, 1999: 75), la realidad fue que entre los exiliados españoles Ilegaron también muchos intelectuales (profesores, filósofos, escritores, músicos, actores, pintores...) y profesionales (médicos, farmacéuticos, biólogos, ingenieros, arquitectos...) (Bru, 1989: 21). El perfil

9 Estimación realizada a partir de datos referidos por Cano et al. (2009:13-15) y MESS (2014).

${ }^{10}$ El término coño es utilizado en Chile para referirse de manera algo despectiva a una persona de nacionalidad española (RAE, 2014); el origen de la expresión parece estar en el uso que los españoles hacen de la interjección "coño", que resulta inusual en el habla chileno y que, por tanto, sirve para identificar a los españoles. de estos emigrantes era diferente al de la anterior oleada, ya que no llegaban buscando mejorar su situación económica, sino refugio ante la guerra civil y la persecución política; los españoles que Ilegaron a Chile en este período no solo dinamizaron, como obreros y como empresarios, algunos sectores de la economía nacional, como la construcción, la pesca o la industria conservera, sino también el ámbito de la cultura y las artes (Guasch, 2011: 39-40).

Actualmente y a partir del 2008, Chile vive una nueva e importante entrada de españoles, aunque por el momento difícil de cuantificar por cuanto se encuentra en curso, y a la que podríamos denominar como "la tercera oleada de coños". El perfil de estos españoles parece ser el de jóvenes con muy alta cualificación académica que buscan en Chile las oportunidades que su país no les ofrece y que se consideran a sí mismos "exiliados económicos", ya que la mayoría no ha elegido abandonar su país, sino que se han visto obligados a ello por la situación de crisis económica. Desde 2008 el número de españoles que Ilega anualmente a Chile se ha triplicado, si lo comparamos con el de españoles que Ilegaban a principios de la década del 2000 (Figura № 1); así, entre 2008 y 2013 han Ilegado a Chile más de 5.000 españoles.

Las entradas de españoles en Chile se dispararon sobre todo a partir de 2010 (cuando el gobierno chileno puso en marcha nuevas políticas de captación de mano de obra extranjera, en este caso de alta cualificación, para impulsar un nuevo ciclo expansivo de la minería chilena), y sobre todo en 2013 (después de que se publicase en diversos medios de comunicación españoles que Chile necesitaría 200.000 nuevos trabajadores cualificados entre 2013 y 2020) (Barreno, 2012). Y es de esperar que sigan Ilegando más españoles a un ritmo similar mientras perdure la escasez de oportunidades laborales en España; aunque también debemos de tener en cuenta que la paralización de muchos proyecto mineros, así como la desaceleración que sufre la economía chilena desde 2013, pueden frenar esta oleada.

Sin embargo, si tomamos los datos de la Estadística de Migraciones del INE-E (2014b) para el período 2008-2013 (cuyos resultados 
Figura $\mathrm{N}^{\circ} 1$

Emigración española a Chile (2002-2013) - datos absolutos

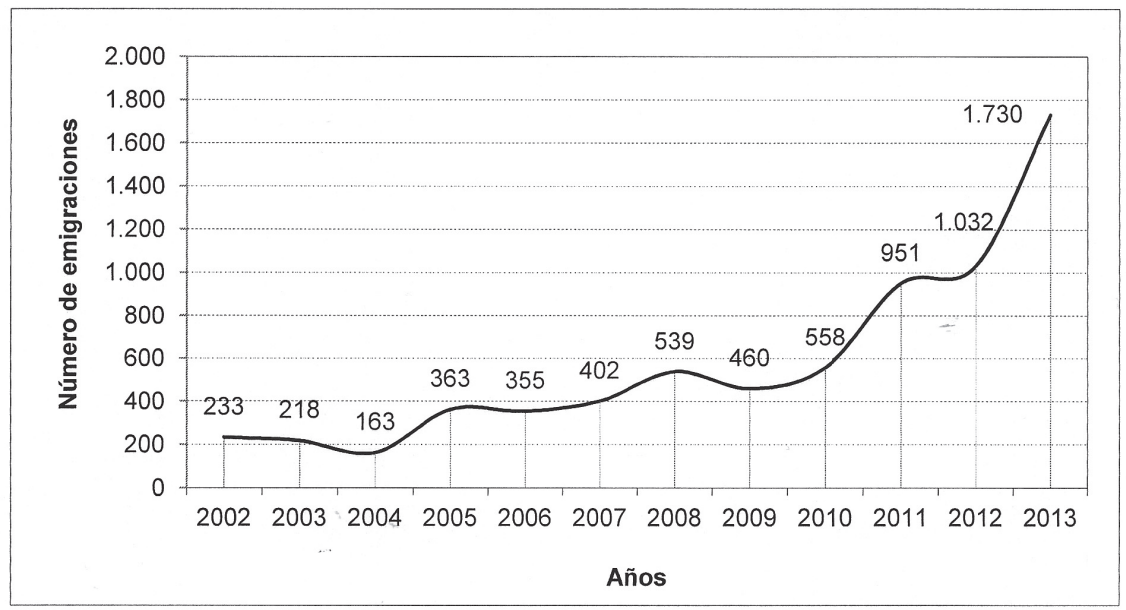

Fuente: Elaboración propia en base a datos de INE-E (2014c).

Figura $\mathrm{N}^{\circ} 2$

Emigración española a Chile por país de nacimiento (2008-2013) - datos absolutos

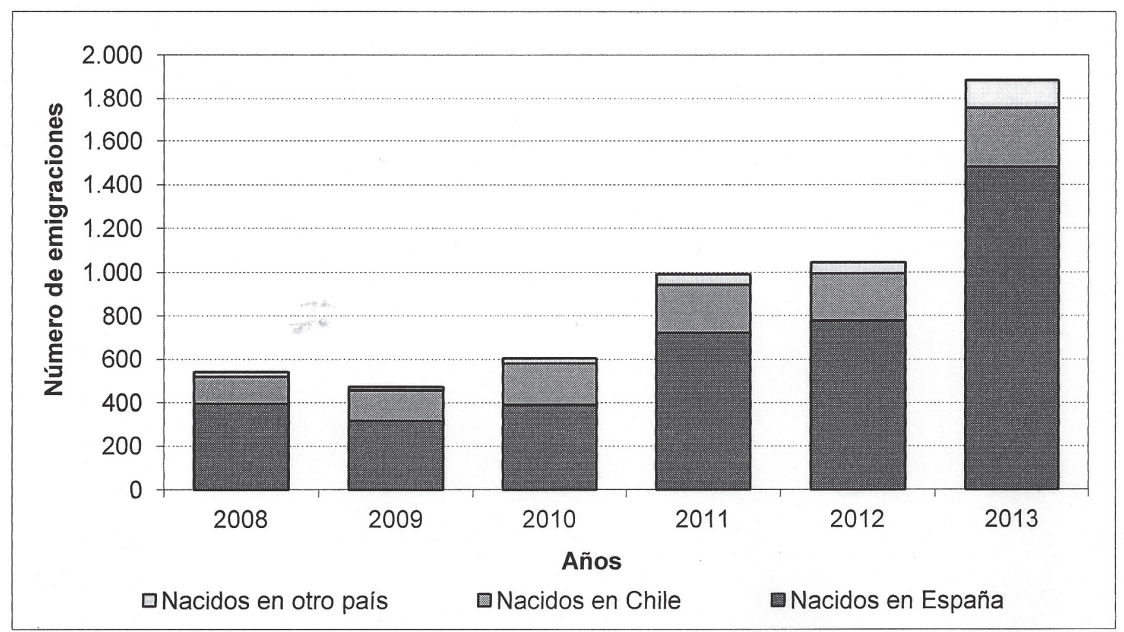

Fuente: Elaboración propia en base a datos de INE-E (2014b).

varían ligeramente respecto de los procedentes de la EVR), podemos apreciar como una parte importante de dicha emigración (poco más de 1.160 emigraciones) la realizan españoles nacidos en Chile, por lo que la emigración de españoles nacidos en España se movería en torno a las 4.100 emigraciones entre 2008 y 2013 (Figura No 2) ${ }^{11}$.

\footnotetext{
11 En este trabajo nos hemos centrado en estudiar la nueva emigración española a Chile de españoles nacidos en España mayores de edad, característica que tienen en común todos los entrevistados, dado
} 
Cabe señalar que esta oleada migratoria de españoles en Chile no solo llega buscando empleo, sino también creando empresas o abriendo negocio en el país, sobre todo en los sectores de la energía y la minería (EFE ECONOMÍA, 2014); algo a lo que contribuyen sin duda las facilidades que ofrece el gobierno chileno para la creación de empresas $^{12}$, la inversión extranjera directa y la contratación de recursos humanos extranjeros ${ }^{13}$.

\section{El perfil sociodemográfico de los españoles emigrados a Chile en la actualidad}

Si damos por representativos los datos de la Estadística de Migraciones (INE-E, 2014b), lo primero que podemos constatar es una cierta masculinización de la nueva emigración española a Chile entre 2008 y 2013, con un $56,8 \%$ de hombres frente a un $43,2 \%$ de mujeres. Sin embargo, si tomamos en cuenta solamente los emigrantes españoles en edad de trabajar en Chile (mayores de 14 años) la masculinización se acentúa pasando las proporciones a ser de $58,3 \%$ y del $41,7 \%$, respectivamente, con 16,6 puntos de diferen$\mathrm{cia}^{14}$. Dicha masculinización es un poco mayor que la presente en el mercado laboral español durante el periodo 2008-2014, donde los hombres activos representan entre el 57\% de 2008 y el $54,2 \%$ de 2014 y las mujeres entre el $43 \%$ de 2008 y el $45,8 \%$ de $2014^{15}$.

que la emigración de españoles nacidos en Chile (en su mayoría chilenos nacionalizados españoles) y de españoles nacidos en otros países (en su mayoría extranjeros de otros países nacionalizados españoles), además de ser minoritaria, presenta unas características muy específicas y diferentes (migración de retorno, migración de cónyuges y descendientes con doble nacionalidad que emigran junto al español nacido en España...).

12 En Chile se tardan cinco días en tramitar el alta de una empresa y uno si se hace a través de Internet.

${ }^{13}$ El Programa Startup Chile concede subvenciones a para la captación de recursos humanos cualificados del extranjero y para el desarrollo empresarial.

${ }^{14}$ La distribución por sexos de nuestros entrevistados es del $43,6 \%$ de hombres frente al $56,4 \%$ de mujeres.

15 Según datos de la EPA de los años que van desde 2008 al 2014 (INE-E, 2014a).
Por lo que se refiere a las edades de los emigrantes españoles, estos son mayoritariamente jóvenes (el 54\% tiene menos de 35 años), siendo los emigrantes entre 25 y 34 años el mayor grupo etario con un 31\% (Figura $\mathrm{N}^{\circ} 3$ ). Aunque si descontamos a los emigrantes que no tienen edad de trabajar, los jóvenes entre 14 y 34 años representarían el $37 \%$, cinco puntos por encima del número de emigrantes españoles que tienen de 35 a 54 años (INE-E, 2014b).

Respecto del origen de los emigrantes españoles, estos proceden de todas las comunidades autónomas, aunque destacan los procedentes de Andalucía, Madrid y Cataluña, que son las comunidades más pobladas de España ${ }^{16}$ y Andalucía, en particular, la que posee una mayor tasa de desempleo ${ }^{17}$. Más del $20 \%$ de los emigrantes proceden de Andalucía y entre el $10 \%$ y el $20 \%$ de Madrid y de Cataluña (INE-E, 2014c).

En relación con el destino de los nuevos emigrantes españoles, según se desprende de nuestras entrevistas, estos se han establecido fundamentalmente en las regiones del centro de país, como ya sucediera con las anteriores oleadas migratorias de españoles, contribuyendo a aumentar la comunidad española en Chile, que ya es la sexta comunidad extranjera por nacionalidad más numerosa del país, tras las de Perú, Argentina, Bolivia, Ecuador y Colombia (INE-C, 2013). Según los datos del PERE, a 1 de enero de 2014 residían en Chile 56.104 españoles, aunque tan solo 8.428 habían nacido en España (INE-E, 2014d), lo cual se explica, fundamentalmente, por la doble nacionalidad chilena y española de la que disfrutan los descendientes de las dos primeras oleadas de coños. Aunque, según estimaciones del Departamento de Extranjería y Migración de Gobierno de Chile, en el 2014 residen en Chile 12.926 españoles (Flores, 2014).

\footnotetext{
16 Según el Padrón Municipal (INE-E, 2014e), Andalucía tiene en 2014 alrededor de 8,3 millones de habitantes, Cataluña 7,5 y Madrid 6,4 frente a los cerca de los 47 millones de toda España.

17 Según datos de la EPA (INE-E, 2014a), la tasa de desempleo en Andalucía es la mayor de España y ha pasado del $17,8 \%$ de 2008 al $34,9 \%$ en el 2014 .
} 
Figura $\mathrm{N}^{\circ} 3$

Emigración española a Chile (2008-2013) por grupos de edad-datos relativos

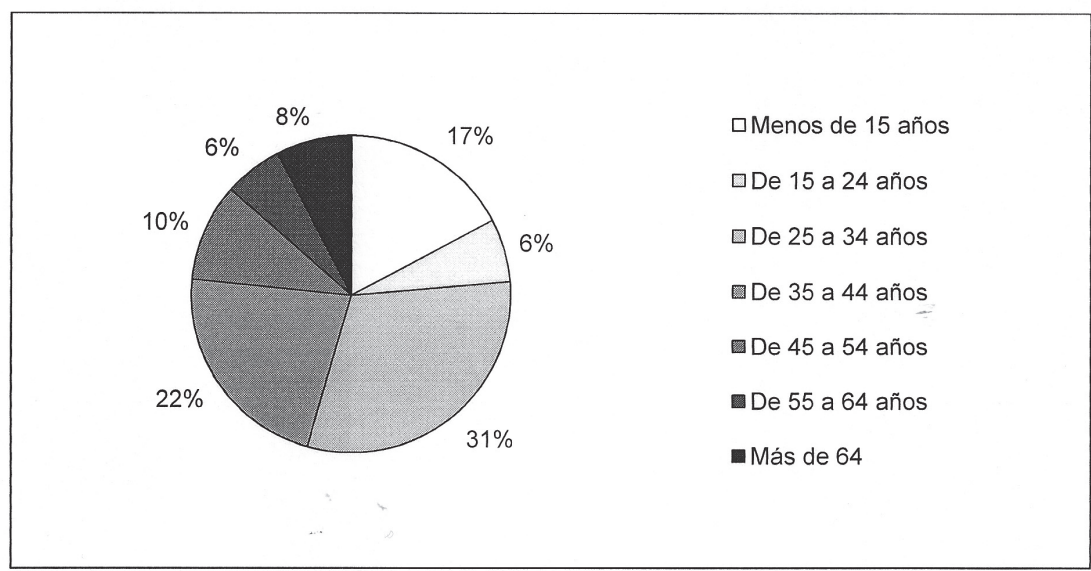

Fuente: Elaboración propia a partir de datos de INE-E (2014b).

La mayoría de los nuevos emigrantes españoles viven en Santiago (casi el $75 \%$ de los entrevistados), Valparaíso y Coquimbo (entre el $5 \%$ y $10 \%$ ). Destaca una mayor presencia de emigrantes en Santiago, como suele suceder en casi todos los destinos migratorios.

En cuanto al estado conyugal, hay menos españoles casados legalmente (poco menos de un tercio de los entrevistados) que solteros, divorciados, separados y viviendo en pareja (poco más de dos tercios), aunque un importante porcentaje (algo menos del $45 \%$ de los entrevistados) o están casados o viven en pareja. $Y$ aunque nos encontramos con parejas mixtas, en las que uno de sus miembros es de origen chileno, la gran mayoría de las parejas son de españoles nacidos en España que han iniciado juntos el proceso migratorio o que, una vez que uno de ellos se ha instalado en Chile, la pareja ha emigrado con posterioridad.

Figura $\mathrm{N}^{\circ} 4$

Nivel de estudios de los nuevos emigrantes españoles entrevistados (2008-2014)

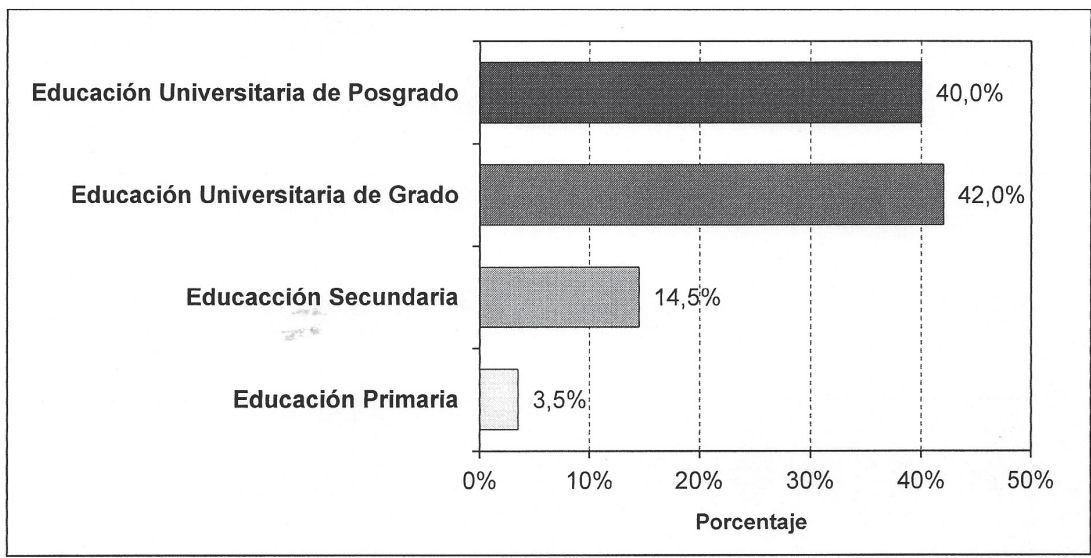

Fuente: Elaboración propia a partir de datos de las entrevistas realizadas. 
"La causa de venir a Chile fue que mi chico encontró trabajo aquí. Él vino primero y a los tres meses vine yo" (mujer, 25 años).

Por otro lado, podemos afirmar que los nuevos emigrantes españoles son trabajadores altamente cualificados (Figura $\mathrm{N}^{\circ} 4$ ). La inmensa mayoría posee estudios universitarios ( $82 \%$ de los entrevistados), casi la mitad de ellos con estudios de posgrado (40\%), e incluso dentro de estos últimos hay un pequeño grupo con estudios de doctorado $(3,5 \%)$. El resto de los trabajadores españoles $(18 \%)$ posee estudios de educación secundaria $(14,5 \%)$ o primaria $(3,5 \%)$. Todo ello nos indica que a Chile está llegando un valioso capital humano en el que la sociedad chilena no ha tenido que invertir, por cuanto se ha formado en España con recursos públicos y privados de la sociedad española; se trataría por tanto de una fuga de talento o brain drain (Adams, 2003).

\section{Las causas de la nueva emigración española a Chile}

La mayor parte de la literatura sobre las múltiples causas de los flujos migratorios (excluidos los flujos de refugiados) se centra en explicar la movilidad laboral entre países en desarrollo y países desarrollados (Arango, 2003; Alonso, 2011; Hidalgo-Capitán, 2013). No obstante, algunas de las explicaciones aportadas son útiles para comprender la nueva emigración española a Chile.

Una de las explicaciones tradicionales de los flujos migratorios se basa en la teoría de la brecha salarial (Harris \& Todaro, 1970) que, combinada con la teoría de la segmentación de los mercados de trabajo (Piore, 1979), debería explicar la movilidad de los trabajadores del subsegmento superior del segmento primario del mercado laboral, que se encuentra globalizado y que está formado por profesionales altamente cualificados y bien retribuidos $y$, a veces, muy disputados por las empresas transnacionales (HidalgoCapitán e Iglesias, 2011: 225-226).

Sin embargo, el salario promedio de los profesionales chilenos se estimó en 2.822
\$ PPA ${ }^{18}$ en $2012(\$ 949.832 \text { o } 1.498 €)^{19}$ frente a 4.280 \$PPA (\$1.842.470 o 2.915 $€)^{20}$ que perciben en promedio los profesionales en España; aun así, la disparidad salarial es muy grande en función no solo del nivel educativo ${ }^{21}$, sino también de la especialidad en la que se posee la titulación (Cuadro $\mathrm{N}^{\circ} 1$ ) y del tipo de contrato (ordinario o como expatriado).

Aunque hay otras explicaciones más plausibles que la brecha salarial. Así, por ejemplo, cuando en una sociedad relativamente equitativa se produce un brusco aumento de la desigualdad, las expectativas de progreso de una gran parte de la población se ven frustradas, se dispara la tasa de emigración y los nuevos emigrantes se dirigen a aquellos países donde perciben un mayor grado de certidumbre (Alonso, 2011: 18-20).

Esto es precisamente lo que ha ocurrido en España como consecuencia de la crisis económica desde 2008, porque la tasa de desempleo de la economía española pasó del $11,3 \%$ en 2008 al $26,5 \%$ en 2014 (INE-E, 2014a), mientras que la tasa de desocupación de la economía chilena pasó del $7,7 \%$ al 6,5\% en el mismo período (INE-C, 2014: 8). Y la tasa española de desempleo juvenil (menores de 25 años) pasó del $21,3 \%$ en el primer trimestre de 2008 al $53,1 \%$ en el primer trimestre de 2013 (INE-E, 2014a).

De hecho, las desiguales evoluciones de las economías chilena y española (Figura $\mathrm{N}^{\circ}$

${ }^{18}$ Dólares de internacionales o en paridad de poder adquisitivo. El uso de dólares PPA permite comparaciones internacionales que evitan el efecto que tienen los diferenciales del coste de la vida en diferentes países; en los casos de Chile y España los factores de conversión en 2012 eran 0,7 y 0,9, respectivamente.

${ }^{19}$ Se ha tomado como referencia el ingreso promedio mensual de los ocupados con "educación universitaria" de grado de la Nueva Encuesta Suplementaria de Ingresos del INE-C (2012).

${ }^{20}$ Se ha tomado como referencia la ganancia media anual por trabajador de "Otros técnicos profesionales científicos e intelectuales" de la Encuesta Anual de Estructura Salarial del INE-E (2012).

${ }^{21}$ El salario promedio mensual de los ocupados con "postítulos o maestría" era en 2012 de \$ 4.170 PPA $(2.840 €)$ y el de aquellos con un "doctorado" de 4.984 \$ PPA (3.333 €) INE-C (2012). 
Cuadro $\mathrm{N}^{\circ} 1$

Salarios medios mensuales chilenos según titulaciones (estimación)

\begin{tabular}{|c|c|c|c|c|c|}
\hline \multicolumn{3}{|c|}{ Grupos de titulaciones mejor pagadas } & \multicolumn{3}{|c|}{ Grupos de titulaciones peor pagadas } \\
\hline Grupos de titulaciones & $\begin{array}{l}\text { Salario } \\
\text { mensual } \\
\text { en pesos } \\
\end{array}$ & $\begin{array}{c}\text { Salario } \\
\text { mensual } \\
\text { en \$ PPA } \\
\end{array}$ & Grupos de titulaciones & $\begin{array}{c}\text { Salario } \\
\text { mensual } \\
\text { en pesos } \\
\end{array}$ & $\begin{array}{c}\text { Salario } \\
\text { mensual } \\
\text { en \$PPA } \\
\end{array}$ \\
\hline Ingeniería civil en minas & 2.517 .500 & 7.480 & Educación de párvulos & 269.422 & 800 \\
\hline Geología & 2.240 .166 & 6.656 & Educador diferencial & 278.771 & 828 \\
\hline Medicina & 1.505 .833 & 4.474 & $\begin{array}{l}\text { Técnico dental y asistente } \\
\text { de odontología }\end{array}$ & 349.968 & 1.040 \\
\hline Ingeniería civil mecánica & 1.436 .416 & 4.268 & $\begin{array}{l}\text { Técnico laboratorista } \\
\text { dental }\end{array}$ & 350.146 & 1.040 \\
\hline Ingeniería civil industrial & 1.395 .583 & 4.147 & Técnico en servicio social & 353.854 & 1.051 \\
\hline Ingeniería civil eléctrica & 1.375 .000 & 4.086 & $\begin{array}{l}\text { Técnico en gastronomía y } \\
\text { cocina }\end{array}$ & 357.385 & 1.062 \\
\hline Ingeniería civil & 1.375 .000 & 4.086 & $\begin{array}{l}\text { Secretariado } \\
\text { computacional }\end{array}$ & 362.781 & 1.078 \\
\hline Ingeniería comercial & 1.149 .250 & 3.415 & Diseño gráfico & 368.865 & 1.096 \\
\hline Ingeniería en electricidad & 1.122 .500 & 3.335 & Técnico agropecuario & 372.195 & 1.106 \\
\hline $\begin{array}{l}\text { Ingeniería en } \\
\text { computación e } \\
\text { informática }\end{array}$ & 995.083 & 2.957 & Secretario ejecutivo & 374.145 & 1.112 \\
\hline
\end{tabular}

Nota: El salario promedio de los profesionales en Chile era en 2012 de \$949.832 o 2.822 \$ PPA. Fuente: Elaboración propia a partir de datos del Ministerio de Educación de Chile (2014).

Figura $\mathrm{N}^{\circ} 5$

Crecimiento económico de Chile y España (2003-2014)

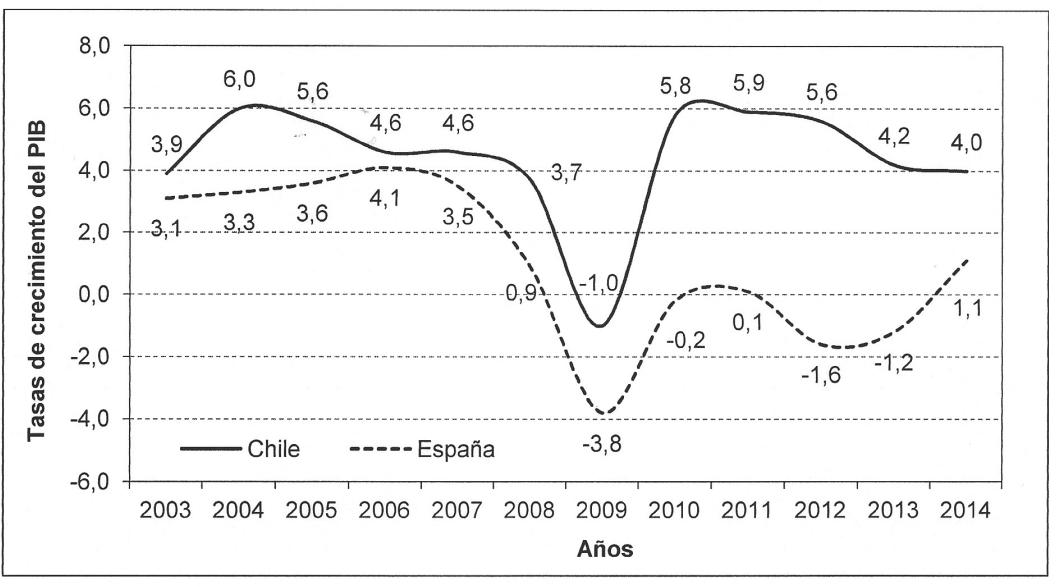

Nota: Los datos de 2013 y 2014 son estimaciones de la CEPAL y la Comisión Europea. Fuente: Elaboración propia a partir de datos del CEPAL (2014) y Comisión Europea (2014). 
5), y en particular la crisis económica, está considerada como la principal causa de la nueva emigración española a Chile (así los afirman casi el 90\% de los entrevistados); y, al igual que ocurriera durante la "primera oleada de coños", no parecen ser ni las diferencias salariales ni las diferencias en los niveles de ingresos entre España y Chile $^{22}$ las que explican los flujos migratorios, sino las oportunidades de promoción social y económica que ofrece Chile (Alonso, 2011: 9).

Así la crisis económica que está viviendo España conlleva que el mercado laboral no ofrezca las oportunidades deseadas para aquellas personas tituladas que acaban de terminar sus estudios, no pudiendo desarrollar su carrera profesional en el ámbito deseado. Esto lleva a muchos jóvenes a buscar esta oportunidad de desarrollo fuera de su país.

"En España no encontraba trabajo de lo mío (Arquitectura). Quería ganar experiencia" (mujer, 29 años).

Por otro lado, muchos españoles que antes de la crisis gozaban de un estatus socioeconómico medio-alto han visto reducido su nivel de vida, encontrándose, en muchos casos, con deudas contraídas con anterioridad (hipotecas...) a las que tienen que hacer frente y deben, por tanto, emigrar para encontrar un trabajo con el que poder pagarlas.

“Tenía necesidad de pagar una deuda contraída por la quiebra de un negocio y me resultaba imposible encontrar un trabajo pagado decentemente en España" (mujer, 41 años).

Además, la crisis también ha generado un empeoramiento de las condiciones laborales en España y por ello algunos españoles, aun conservando su trabajo, deciden buscar otro fuera con mejores condiciones.

\footnotetext{
22 Según datos de la Organización Internacional de Trabajo (citados por BBC, 2012), el sueldo medio mensual estimado en España era de \$2.352 PPA en 2009, mientras que en Chile era de 1.021 \$ PPA; además, según datos de la OCDE (2013), el PIB per cápita de España era en 2013 del 32.614 \$ PPA frente a los \$21.990 PPA de Chile.
}

"En mi antigua empresa trabajaba a jornada reducida y no me habían pagado en los últimos tres meses. Decidí buscar trabajo en Chile porque tenía conocidos" (hombre, 27 años).

También es muy significativo el hecho de que solo una pequeña proporción de los nuevos emigrantes españoles a Chile (en torno al $10 \%$ de los entrevistados) envía remesas a España. Esto se explicaría por el hecho de que estos emigrantes han iniciado el proceso migratorio empujados por su situación económico-laboral personal, y no tanto por su situación económica familiar; de hecho, la emigración en muchos casos coincide con la emancipación de los jóvenes de sus familias y con la formación de nuevas familias ya en el extranjero.

"En España era impensable emanciparnos de la casa de nuestros padres y plantearnos formar una familia" (mujer, 25 años).

Por el lado chileno, el principal factor de atracción de emigrantes españoles es el nuevo ciclo expansivo de la minería chilena. Debe tenerse en cuenta que la minería representa el $13 \%$ del PIB y el $60 \%$ de las exportaciones chilenas y que dicho sector lidera el desarrollo de las regiones del norte de Chile, que es el principal exportador mundial de cobre (Villarino, 2013: 5), a lo que hay que unir la fuerte subida del precio del cobre en los mercados internacionales de commodities ${ }^{23}$. $\mathrm{Si}$ tenemos en cuenta que el neoextractivismo se ha convertido en el nuevo modelo de desarrollo de las economías andinas (Acosta, 2012) y que Chile debe enfrentar una fuerte competencia por parte de sus vecinos (en especial Perú y Argentina), se entiende la preocupación del gobierno chileno por aumentar la productividad de la mano de obra dedicada a la minería, algo que implica contar con nuevas tecnologías y con recursos humanos cualificados, y este país no dispone de suficiente fuerza laboral cualificada para las demandas del $\operatorname{sector}^{24}$ (La Segunda,

\footnotetext{
${ }^{23}$ El precio del cobre pasó de los \$ 0,60 por libra en 2003 a los \$ 3,5 por libra en 2013 (BCC, 2013: 37).

${ }^{24}$ Se ha estimado que Chile necesitaría 38.000 nuevos trabajadores entre 2011 y 2020 (INNOVUM, 2011), aunque algunos medios españoles llegaron a publi-
} 
2013: 48-49). Todo ello ha atraído a muchos emigrantes españoles que han Ilegado a Chile para trabajar en los sectores de la minería y la energía (más del 40\% de los entrevistados).

"He estudiado geología y Chile es un país dedicado a la minería. Eché diferentes candidaturas y una empresa de Chile me contrató" (hombre, 25 años).

Por otro lado, la existencia de redes migratorias entre dos países, entendidas como el conjunto de relaciones interpersonales que vinculan a los emigrantes reales o potenciales con parientes y amigos del país de destino, incluso aunque residan en el país de origen (Arango, 2003: 9), aumentan la posibilidad de que se produzca una emigración entre ellos, dado que reducen los costes y riesgos del movimiento e incrementan los beneficios netos previsibles (Massey et al., 1994: 485490). Dichas redes forman parte del capital social o relacional que facilita el proceso migratorio, ayuda a perpetuarlo y condicionan el retorno. Igualmente influye en la conformación de redes migratorias la existencia de una lengua y una cultura común (PNUD, 2009: 24).

Chile y España conforman un sistema migratorio desde hace siglos, y la numerosa comunidad española en Chile facilita el proceso de migración. De hecho la mayoría de los nuevos emigrantes españoles (el $75 \%$ de los entrevistados) contaban con vínculos sociales en Chile (familiares, parejas o amigos). La existencia de lazos familiares debidos a migraciones anteriores, junto con la posibilidad de vivir en un país con la misma lengua, son señalados como factores relevantes a la hora de elegir Chile como destino del proceso migratorio.

"Conocía a gente de aquí que podían facilitar mi contacto inicial con el país" (mujer, 30 años).

No parece que la distancia entre España y Chile haya sido un impedimento para la conformación de este sistema migratorio interre-

car que dicha demanda sería de 200.000 trabajadores (Barreno, 2012). gional, habida cuenta de que en la actualidad los mismos medios de transporte que utilizan los turistas españoles para viajar a Chile son los utilizados por los nuevos emigrantes españoles (Hidalgo-Capitán, 2013); de hecho, algunos de los nuevos emigrantes habían estado antes en Chile como turistas o Ilegaron como turistas y decidieron quedarse como emigrantes. La fuerte competencia entre aerolíneas americanas (LAN, Avianca, Aerolíneas Argentinas...) y europeas (Air Europa, Air France...) que conectan diferentes ciudades españolas y chilenas ha hecho que puedan obtenerse pasajes aéreos con un coste cercano a los $300 €$ por trayecto, precio muy asumible para los niveles medios de renta de las familias españolas.

"Había venido de vacaciones y conocía gente de aquí que me apoyaron para comenzar" (mujer, 24 años).

También las nuevas tecnologías e Internet contribuyen a reforzar este sistema migratorio, por cuanto optimizan y amplían la información y el acceso a redes sociales de españoles que se encuentran en Chile. Existen grupos creados por Facebook que ofrecen información, tanto para españoles que acaban de llegar, como para aquellos que tienen intención de emigrar, y más de la mitad de los nuevos emigrantes españoles (poco más del $50 \%$ de los entrevistados) ha ayudado a otros españoles en su proceso migratorio. Desde estos grupos se realizan "quedadas" con la intención de afianzar lazos entre los españoles emigrados.

Otras de las causas que suele considerarse importante para explicar los flujos migratorios es la frustración social de aquellos individuos que perdieron la lealtad hacia las instituciones y desconfían de poder articular una voz colectiva que promueva un cambio social (Hirschman, 1977; Alonso, 2011: 22); la emigración se convierte así en una válvula de escape de las crisis sociales y en una denuncia silenciosa de la falta de una respuesta colectiva (Ellerman, 2003; Li \& McHale, 2009). En el caso de los nuevos emigrantes españoles, muchos de ellos están implicados de forma activa en diferentes movimientos sociales, como el 15M, Marea Granate o Podemos Chile, y participan en actos políticos de protesta, como los organizados por \#NoNos- 
VamosNosEchan 25. Estos miran a España con desesperanza ante unas políticas económicas que no parecen dar resultado y dudan de que la economía española vuelva a medio plazo a la senda del crecimiento. Esta desesperanza les induce a considerarse a sí mismos como "exiliados económicos", afirmando que han sido expulsados de España por culpa de la falta de oportunidades.

"Yo me considero eso que se llama 'exiliado económico' y considero que la posibilidad de residir en un país extranjero es una experiencia única que hace que crezcas a nivel personal. Independientemente de que te vaya bien o mal, al final todo es un aprendizaje. El problema viene cuando, esa decisión de tener un 'espíritu aventurero' es totalmente impuesta. Elegí Chile por sus posibilidades laborales y punto. No lo elegí por su calidad de vida u otros temas, que son las cosas que uno tiene en cuenta más conscientemente cuando emigra voluntariamente" (hombre, 30 años).

Por otro lado, la expansión internacional del capital en forma de empresas transnacionales contribuye a que muchos países relajen sus políticas migratorias respecto de las demandas de profesionales cualificados de dichas compañías, cuyos trabajadores de mayor nivel son seleccionados desde las casas matrices de dichas compañías (Sassen, 1998). En el caso chileno, el principal origen de la inversión extranjera directa (IED) que recibió el país entre 2009 y 2012 fue España, de donde procedió el $12,9 \%$ de la IED de dicho período (10.504 millones de dólares) (CHC, 2014). Mientras que Chile es el tercer país de destino de la inversión de las empresas españolas, por detrás de Brasil y México.

\footnotetext{
25 El Movimiento 15-M, también Ilamado movimiento de los indignados españoles, es un movimiento ciudadano formado a raíz de la manifestación del 15 de mayo de 2011. Marea Granate es un movimiento transnacional formado por emigrantes de nacionalidad española que luchan desde fuera contra las causas que han provocado la crisis económica y social que les ha obligado a emigrar. Podemos Chile es uno de los círculos del movimiento social y político Podemos, convertido recientemente en partido político en España.\#NoNosVamosNosEchan es una iniciativa promovida por la Plataforma Juventud Sin Futuro que denuncia la situación de exilio forzoso de la juventud española.
}

En 2014 existen 324 empresas españolas instaladas en Chile en diferentes sectores de actividad (servicios de medio ambiente, producción energética, construcción e infraestructuras, ingenierías, servicios de transporte, textiles, etc.). Así podemos encontrarnos con conocidas firmas españolas en confección textil (i.e. Adolfo Domínguez, Zara, Mango), grandes empresas financieras y aseguradoras (i.e. Banco de Santander, BBVA, Caixabank, Banco de Sabadell, Banco Popular) energéticas (i.e. Abantia, Abengoa, Enerficaz), telecomunicaciones (i.e. Telefónica, Avanzit, Energía Contact Center), hoteleras y turísticas (i.e. $\mathrm{NH}$, Alfa Gestión de Patrimonios Hotelero), editoriales (i.e. Planeta), de publicidad e investigación de mercado (i.e. Atento, Agencia Andaluza de Promoción de Exterior, Agencia de Suport a L'empresa Catalana) (ICEX, 2014).

La situación económica de España ha espoleado también el traslado de todo o parte de los negocios de muchas empresas españolas a Chile, sobre todo en los casos de las empresas relacionadas con la minería, la energía y la construcción; y estas empresas han trasladado también a sus empleados. Como es habitual, las condiciones laborales de estos, como "expatriados", son notablemente mejores que las que tenían en España.

"La causa del por qué me vine a Chile fue por la expatriación de la empresa de construcción en la que trabajo" (mujer, 27 años).

\section{Las dificultades iniciales en el proceso migratorio desde España a Chile}

Una de las primeras dificultades que suele encontrarse un emigrante en la actualidad es la necesidad de obtener un visado previo para poder residir y trabajar en un país extranjero, e incluso para viajar a él (Alonso, 2011: 10).

La pertenencia de España al Espacio de Schengen ${ }^{26}$, con el que Chile tiene un acuer-

\footnotetext{
26 El Espacio Schengen es un espacio formado por 26 países europeos que han eliminado las fronteras entre ellos estableciendo fronteras comunes frente a terceros países.
} 
do de reciprocidad, exime a los españoles de la necesidad de disponer de una visa chilena para permanecer en el país como turista hasta 180 días; y esto ha facilitado el que un importante número de españoles Ilegasen a Chile con la intención de encontrar primero un empleo y solicitar el permiso de trabajo después, durante los seis meses de estancia máxima posible sin visado.

En principio, para poder trabajar en Chile, un extranjero necesita una visa de trabajo y para ello debe tener un contrato de trabajo formalizado en su país de origen; sin embargo, esto es difícil de conseguir y liga forzosamente al emigrante con la empresa que lo contrate, imposibilitándole trabajar con otra. Existe, no obstante, otra opción que es incluso más conveniente y es a la que recurren muchos españoles; se trata de solicitar la visa temporaria una vez que se ha entrado en el país como turista; esta visa permite residir en Chile durante un año y realizar cualquier actividad sin limitaciones.

Para obtener la visa temporaria desde Chile no existe mayor problema si se posee un título universitario, ya que se entiende que las personas con alta cualificación son de utilidad para el país; los requisitos que se solicitan son que el inmigrante se encuentre en situación legal como turista y que posea una oferta o contrato de trabajo y un título universitario homologado. Las ventajas que tiene esta opción es que es más fácil de conseguir, que la oferta de trabajo no liga al inmigrante con la empresa y que puede ser utilizada también por inmigrantes sin estudios universitarios (aunque en este caso se les solicitan dos o más contratos firmados ante notarios). La mayoría de los inmigrantes españoles que Ilegan a Chile sin visa de trabajo (en tono al $79 \%$ de los entrevistados) no encuentran problemas para regularizar su situación.

"No he tenido grandes problemas en encontrar empleo; una vez que he homologado mi título, no he tenido mayores inconvenientes en encontrar empresas que me hicieran la carta de oferta para conseguir la visa de trabajo" (mujer, 32 años).

Al margen de los problemas legales, el proceso migratorio tiene un importante coste económico en forma de gastos de viaje y fon- do de subsistencia hasta encontrar empleo, por lo que se requiere de un capital mínimo (Barham \& Boucher, 1998). Muchos de los nuevos emigrantes españoles (en torno al $48 \%$ de nuestros entrevistados) han necesitado la ayuda de familiares y amigos para hacer frente a los costes del viaje y de los primeros meses lo que pone de manifiesto que las familias son, en muchos casos, la unidad de referencia de la decisión migratoria (Barham \& Boucher ,1998).

"Mi madre me ayudó comprando los billetes de avión y unos amigos que tenía ya aquí me ayudaron económicamente facilitándome cheques y aval para arrendar el departamento en el que estoy" (mujer, 33 años).

En el caso de muchos de los españoles que han llegado con un contrato de trabajo desde origen (casi el $21 \%$ de nuestros entrevistados), ha sido la propia empresa la que se ha hecho cargo del coste del billete y de la estancia de los primeros meses.

"En la propuesta de contrato la empresa se comprometía a que, pasado el periodo de tres meses de prueba, ellos se harían cargo de parte de los pasajes. Concretamente con el correspondiente a MadridSantiago de Chile" (hombre, 30 años).

Las becas internacionales de estudio y prácticas en el extranjero (Programa de Cooperación Interuniversitario con Iberoamérica de la Agencia Española de Cooperación Internacional para el Desarrollo, Ayudas de Movilidad de la Asociación Universitaria Iberoamericana de Posgrado, Becas Iberoamericanas del Grupo Santander...), la participación en proyectos de cooperación al desarrollo y en proyectos internacionales de investigación subvencionados por las administraciones públicas españolas y por algunas entidades privadas, también constituyen una vía para aquellos jóvenes españoles que quieran iniciar su proceso migratorio. Pero debido a la crisis económica que está padeciendo España y los ajustes presupuestarios públicos y la reducción de las partidas privadas destinadas a responsabilidad social corporativa y a investigación y desarrollo, han disminuido sustancialmente esta vía de financiación. 
No obstante, esta reducción se ha visto compensada en parte por los diferentes programas chilenos de atracción de recursos humanos cualificados del exterior. Entre estos destaca el Programa Académico Internacional Regular (PAIR) de la Universidad de Chile (Zamora, 2012), empeñada en contratar doctores extranjeros y que se ha nutrido desde 2012 esencialmente de doctores españoles ${ }^{27}$ y el Programa Startup Chile, que financia proyectos empresariales de alto potencial de crecimiento. Ambos programas facilitan todos los trámites burocráticos y cubren con todos los gastos para poder emigrar a Chile.

"Startup Chile me ha regularizado la situación en el país en menos de una semana y me ha pagado todos los costes del viaje" (mujer, 26 años).

\section{La situación actual de los nuevos emigrantes españoles en Chile}

Los españoles que han emigrado a Chile se concentran fundamentalmente en Santiago ( $74,5 \%$ de nuestros entrevistados), Valparaíso $(6,4 \%)$ y Coquimbo $(5,5 \%)$; y Santiago es una de las ciudades más caras del mundo para vivir (la número 88) y la sexta ciudad más cara de América Latina (Mercer, 2014). Lógicamente, el nivel de vida depende del salario que se cobre y este del tipo de cualificación que se tenga.

Los salarios de los emigrantes españoles que cuentan con titulación y visado difieren sustancialmente de aquellos que no disponen de los mismos; y además tanto el sueldo como las condiciones laborales que se ofrecen en Chile a los trabajadores no cualificados son inferiores a las ofrecidas en España. Casi la mitad de los nuevos emigrantes españoles (el $49 \%$ de los entrevistados) cobra un salario que está por encima del sueldo medio chileno (1.021 \$ PPA en 2009); mientras que un pequeño porcentaje de $(10 \%$ de los entrevistados) no tiene ingresos propios, bien porque aún no han encontrado empleo, bien

\footnotetext{
${ }^{27}$ Casi el $11 \%$ de nuestros entrevistados trabaja en el sector de la educación.
}

porque han optado por no buscarlo (amas de casa, estudiantes...). La opinión de los nuevos emigrantes españoles sobre las condiciones laborales varía en función de su formación y, en general, los emigrantes empleados en empresas extranjeras localizadas en Chile disponen de mejores salarios y mejores condiciones laborales.

"Tengo condiciones de expatriada, cotizo en España y además de mi sueldo tengo otros beneficios (dietas, seguro médico privado, viajes a España cada tres meses, más días de vacaciones)" (mujer, 30 años).

$Y$ aunque muchos emigrantes españoles no perciban una alta retribución económica, sobre todo respecto del alto coste de la vida, Chile sí les brinda buenas oportunidades de adquirir experiencia laboral y de ampliar el currículum, por lo que el factor de oportunidad es lo bastante importante como para iniciar el proceso migratorio.

"Chile no es un país que me haya permitido ahorrar dinero (sueldos bajos y costes de vida altos), pero me ha dado la oportunidad de trabajar de lo que había estudiado (Humanidades)" (mujer, 34 años).

Tal vez por ello, la gran mayoría de los nuevos emigrantes españoles (el 85\% de los entrevistados) se encuentran satisfechos con su emigración a Chile; aun así, se pueden constatar ciertos problemas en el proceso migratorio.

Los mayores problemas que perciben los españoles en Chile, por orden de importancia son (Figura $\mathrm{N}^{\circ}$ 6): los problemas burocráticos; el coste y la calidad de la asistencia sanitaria; las diferencias culturales; las condiciones laborales; el acceso a una vivienda; la inseguridad; y la contaminación.

Uno de los principales problemas con los que se encuentran los españoles emigrados a Chile son los derivados de la burocracia nacional, que se considera lenta y compleja. En muchos casos se percibe que desde los organismos oficiales chilenos no se les da respuesta a sus demandas debido a la falta de información que tienen los propios funcionarios que trabajan en ellos. 
Figura $N^{\circ} 6$

Principales problemas percibidos por los nuevos emigrantes españoles entrevistados (2008-2014)

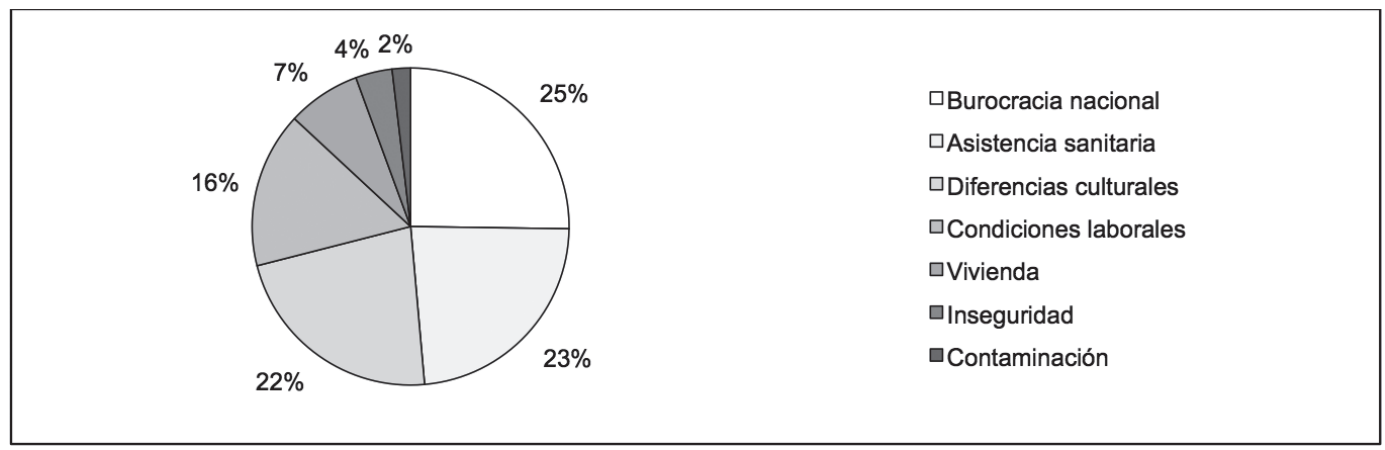

Fuente: Elaboración propia a partir de datos de las entrevistas realizadas.

"Uno de los principales problemas es la burocracia. Llevo más de cinco meses esperando mi visa de residencia definitiva" (mujer, 29 años).

Aquellos españoles que han emigrado a Chile sin antes haber homologado sus títulos universitarios en España se encuentran ante el problema de los trámites que deben realizar para conseguir dicha homologación ${ }^{28}$. Si se requiere realizar el trámite de homologación de títulos estando en Chile se precisan una serie de documentos difíciles de conseguir desde allí (diploma de título o grado en original, expediente académico, plan y programa de estudios, etc.) y el tiempo de la homologación es largo y acarrea costes elevados.

"Al querer legalizar mi título profesional (Psicología) tuve que pagar bastante dinero y el proceso se demoró un año y ocho meses en total. En este país para todo hay trámite y un cobro" (hombre, 39 años).

Abrir una cuenta bancaria también se convierte en una tarea imposible para los españoles que Ilegan a Chile, ya que uno de los requisitos para poder hacerlo es poseer la visa de residencia. Los bancos no abren cuentas a inmigrantes que tengan menos de dos años de residencia y aun así se necesita

\footnotetext{
${ }^{28}$ La homologación de títulos no es obligatoria para todas las profesiones, pero sí para algunas como médicos y docentes.
}

el número de identificación del RUT (Rol Único Tributario; número de identificación fiscal), además de una prueba de ingresos chilenos y un depósito mínimo. Y tener una cuenta bancaria es requisito imprescindible para realizar otro tipo de trámites, como contratar una línea de teléfono, ADSL, etc.

"Es casi imposible abrir una cuenta bancaria y eso conlleva que no puedes tener, por ejemplo, una cuenta de telefonía móvil con contrato" (mujer, 35 años).

Otro de los problemas que perciben los emigrantes españoles está relacionado con el coste y la calidad de la asistencia sanitaria. En Chile la cobertura sanitaria obligatoria de los trabajadores está semiprivatizada y el trabajador debe elegir entre recibirla por medio del Fondo Nacional de Salud (FONASA), entidad pública, o por medio de diversas entidades privadas que conforman el sistema de las Instituciones de Salud Previsional (ISAPRES) y, en ambos casos, rige el principio de copago conforme a baremos fijados por el gobierno.

"Chile es un país que privatizó absolutamente todo. En cuanto a la sanidad yo soy de FONASA y, pese al $7 \%$ de retención de mi sueldo, debo pagar la consulta del médico, la cual tiene un coste de 6,50 € y además las medicinas, etc. Un ejemplo: tuve un problema en el pie que me llevó a acudir a un traumatólogo y luego a un kinesiólogo (10 sesiones); esto, sumado a 
las medicinas, arreglar mi pie (no era fractura, ni esguince y nada serio, ni grave) un total de $117 €^{\prime \prime}$ (hombre, 30 años).

El sistema sanitario público chileno no es solo criticado por el coste del mismo, sino también por su calidad. Los servicios que ofrece la sanidad pública chilena no son de la misma calidad que los que ofrece el sistema sanitario español ${ }^{29}$.

"La sanidad es horrible, da pena ir al hospital y encima te cobran por todo" (hombre, 41 años).

Ante esta situación muchos españoles deciden contratar un seguro médico de alguna de las entidades de ISAPRES, pero para ello se deben cumplir unos requisitos previos de salud o en caso contrario, las compañías pueden negarse a suscribir el contrato o pueden cobrar mayores tasas.

"No puede contratar un sistema privado (ISAPRES) por contar con una preexistencia, enfermedad anterior (diabetes)" (hombre, 32 años).

La privatización de los servicios públicos, en general, se considera un gran problema para el colectivo de españoles que Ilega a Chile; acostumbrados a unos servicios públicos de calidad y universales, no llegan a comprender demasiado bien cómo funciona este sistema, en el que tanto la sanidad como la educación, y hasta las pensiones (por medio de la Administradora de Fondos de Pensiones -AFP-), están en manos de empresas privadas.

"Del total del sueldo tengo una retención del $20 \%$, la cual se divide en un $7 \%$ para cobertura sanitaria y un $10 \%$ el sistema

\footnotetext{
${ }^{29}$ Conviene recordar que el sistema sanitario español está considerado como uno de los mejores de mundo y que, hasta la Reforma Sanitaria de 2012, la asistencia sanitaria en España era universal, gratuita y financiada vía impuestos; desde entonces, en España se ha establecido el copago sanitario en muchas comunidades autónomas, se ha aumentado un $10 \%$ el copago farmacéutico, se han excluido muchos medicamentos de la financiación pública y se le ha retirado la cobertura sanitaria a todas las personas que no puedan acreditar ingresos de origen laboral.
}

de AFP. La AFP es en una empresa privada que utiliza mi sueldo para 'jugar' en bolsa e invertir en lo que ellos decidan; y si el negocio no sale bien y hay pérdidas, no tienen la obligación de compensarme. En este sentido, el sistema chileno te obliga a contratar a la empresa AFP MODELO cuando tienes tu primer contrato, aunque uno procura que lo incluyan en el plan de menor riesgo; este plan tiene menor rentabilidad. En definitiva, aquí uno se paga su propia jubilación. De todos modos, si uno solicita que en el anexo de contrato, la empresa añada un texto en el que diga que tu régimen provisorio te lo vas a llevar a España, una vez que acabes tus actividades en el país, la AFP debe reintegrarte todas las cotizaciones mensuales durante tu estancia. Pero, ¡ojo!, para eso uno tiene que haber cotizado en el sistema de Seguridad Social español, si no es así, uno perdería todo ese dinero una vez que salga del país" (hombre, 30 años).

Pese a las similitudes culturales entre España y Chile (lengua, religión, tradiciones...), existen problemas culturales derivados de la convivencia entre españoles y chilenos. Muchos inmigrantes españoles han vivido escenas xenófobas marcadas por los prejuicios que nacen del miedo a lo desconocido, frases tan escuchadas en España como "los inmigrantes nos quitan el trabajo" son dirigidas ahora hacia ellos, por lo que algunos españoles detectan una cierta discriminación por ser extranjeros.

"La cultura es muy diferente y a veces por ser españoles nos miran raro; además no nos entienden o se hacen los "longis"; tienen una forma de ser muy especial" (mujer, 34 años).

Aunque en España y Chile se hable el mismo idioma, existen diferentes acepciones de las palabras y las expresiones, por lo que, en ocasiones, se producen malos entendidos.

"Aunque compartimos el mismo idioma, tienen otras expresiones, fonética, sinónimos, etc. que al principio no entendía" (hombre, 37 años).

Las condiciones laborales chilenas son también muy criticadas por los emigrantes 
españoles cuando las ponen en comparación con las españolas. En general en Chile se trabajan más horas y hay menos días de vacaciones al año; según el Código del Trabajo de Chile (Dirección del Trabajo, 2014) la jornada laboral no puede exceder de 45 horas semanales (5 más que en España) sin que se puedan trabajar más de 10 horas diarias (1 más que en España) (Cap. IV, Art. 22). Por otro lado, el periodo vacacional es de 15 días al año (la mitad que en España) y solo se puede acceder a él tras un año de trabajo (Capítulo VII, Art.67). Aun así, diferentes testimonios dejan constancia que en Chile hay más oportunidad de crecimiento y proyección profesional que en España.

"Los salarios son buenos, aunque la vida aquí es un poco más cara. La jornada laboral es muy larga en comparación con España, aunque en mi opinión se produce menos. Los días de vacaciones son 15 , pero las posibilidades de promocionar son mayores que en España" (mujer, 33 años).

Las condiciones laborales son diferentes en función del tipo de empresa en la que se trabaje, nacional o extranjera (incluyendo entre estas a las españolas). Los emigrantes españoles trabajan en ambos tipos de empresas (el $51 \%$ de los entrevistados trabaja en empresas, instituciones o fundaciones nacionales chilenas).

"Con la formación y experiencia de esteticista que tengo, aquí solo encuentro trabajo por boletas de honorarios; con lo cual no tienes ni seguro médico, ni vacaciones, ni tampoco incentivos" (mujer de 32 años).

Además, en Chile existen grandes diferencias entre los salarios de los hombres y los de las mujeres, de forma que el sueldo medio mensual de un hombre era de \$500.787 (738 \$ PPA o $821 €$ ) en 2012, mientras que el de las mujeres era de \$338.791 (500 \$ PPA o $555 €$ ), un 32\% inferior (INE-C, 2012: 8); hecho este que no pasa inadvertido para las mujeres emigrantes españolas.

"No me han contratado por ser mujer $y$ algunos trabajos que he realizado no me los han querido pagar (iporque no!); cobro la mitad que mis compañeros (hombres) y tengo más trabajo que ellos" (mujer, 28 años).

La vivienda se considera otro de los mayores problemas a los que se enfrentan los españoles emigrados a Chile. Conseguir un buen alquiler se complica si eres extranjero y no tienes un contrato de trabajo, y los requisitos para poder alquilar varían según la condición en la cual se llegue al país. Si se llega con un contrato de trabajo, suele ser la misma empresa la que sirve de avalista, asegurando que la persona a quien se le está alquilando la propiedad cuenta con los recursos necesarios para hacer frente al pago del alquiler. En el caso de no llegar con contrato de trabajo, la tarea de alquilar se complica y se vuelve más lenta, ya que el arrendador exige al menos las últimas tres nóminas más el respaldo de un avalista con residencia en el país, además de exigir el abono por adelantado de dos o más mensualidades como garantía; y si no dispone de aval se exige el pago por adelantado de todo el periodo de alquiler. Además, elegir bien la comuna en la que se va a residir es imprescindible ya que el coste del alquiler varía significativamente. Así por ejemplo en la centro de Santiago el alquiler de un departamento puede costar unos \$200.000 (260€), mientras que en comunas como Los Condes, Vitacura, Providencia o La Reina el alquiler de un departamento de las mismas características puede llegar a costar hasta \$1.600.000 (2.100 €).

"Fue muy complicado encontrar un departamento para arrendar por el número de papeles y las condiciones que te exigen, como, por ejemplo, un aval chileno" (mujer, 29 años).

La inseguridad en Chile no es demasiado elevada en comparación con la inseguridad en otros países de América Latina (PNUD, 2013: 39). No obstante, sí que existe una gran brecha de desigualdad económica que es percibida como inseguridad por los emigrantes españoles; de hecho Chile es el cuarto país de la OCDE en el que existe una mayor tasa de pobreza relativa, dado que un $18 \%$ de la población tiene ingresos inferiores al 50\% de la media nacional (OCDE, 2014).

"La inseguridad ciudadana es un problema mucho mayor de lo que se suele creer 
desde fuera, especialmente en las grandes ciudades, como Concepción. Existe una pobreza extrema camuflada, denominada localmente 'vulnerabilidad' (personas que viven en condiciones muy precarias pero con subsidios del gobierno que les ha permitido salir de las estadísticas de pobreza extrema)" (hombre, 29 años).

La contaminación es otro de los grandes problemas que vive Chile. Pese a las intervenciones nacionales e internacionales para reducir las principales emisiones contaminantes, los efectos de la contaminación del aire urbano continúan empeorando.

"Hay demasiada contaminación. La ciudad y el país tienen unos sistemas de transporte pésimos. Santiago es muy extenso y es complicado llegar a los lugares. El tráfico es intenso y ves a muy poca gente paseando, salvo en los inmensos centros comerciales" (hombre, 30 años).

\section{Las expectativas de futuro de los nuevos emigrantes españoles en Chile}

En casi todo proceso de migración la perspectiva de retorno está presente, a corto, medio o largo plazo; en el caso de la emigración española a América Latina ("hacer las Américas" ${ }^{\prime 30}$ ) el retorno fue siempre una aspiración, e incluso un reclamo ${ }^{31}$; y prueba de ello es la figura política y literaria española del "indiano" 32 .

“Lo que más desearía es volver a estar con mi familia, volver a trabajar en mi país. Mientras más pasa el tiempo, a muchos, más lejos nos queda la oportunidad de volver a vivir allí. Pasará el tiempo y seremos españoles que van de vacaciones a su tierra. ¡Los que estamos fuera, te queremos, España! ¡Deseamos y soñamos con

\footnotetext{
30 Expresión que podemos encontrar en Mendoza y Ortiz (2006), entre otros.

31 “¡Volved!", reclamaba Rosalía de Castro (1886).

32 Emigrante español en América que retornaba rico y se convertía en líder político y económico en su localidad de origen (De Miguel et al., 1984; Mencos y Bojstad, 1998).
}

poder volver, pero nos han expulsado!" (mujer, 24 años).

La migración de retorno es una experiencia diferente según las distintas condiciones de salida tanto del lugar de origen como del de destino y, además, las causas y los efectos de las migraciones de retorno vienen determinados por el cruce de las principales variables que definen la trayectoria migratoria (Durand, 2004).

Entre las causas que frenan las migraciones de retorno estarían la consolidación de las redes migratorias y la aparición de instituciones y agentes de apoyo a los movimientos transnacionales; gracias a ellos las migraciones internacionales se perpetúan en el tiempo y en el espacio (Massey et al., 2005: 42). La consolidación de las redes sociales facilita especialmente el desarrollo personal y social del emigrante en cualquier país en que se encuentre, al estar en contacto con otras personas en su misma situación, mientras sigue manteniendo los lazos familiares y de amistad con su país de origen. Con las redes sociales consolidadas y unas oportunidades para desarrollarse profesionalmente, la perspectiva de regreso se ve cada vez más lejana. La inestabilidad laboral y económica de España y la creación de familias en el lugar de destino conducen a muchos emigrantes españoles a aplazar el retorno, e incluso a renunciar a él por completo.

"Acá he conocido a mi pareja. Chile me ha dado la oportunidad que España no me ha dado: trabajar en lo que he estudiado. He hecho grandes amigos aquí. La sola idea de volver a un país que me ha robado y expulsado, no la contemplo... aunque eche de menos a mis seres queridos allí" (mujer, 33 años).

El retorno dependerá también del capital social relacional que el emigrante haya adquirido en la sociedad de acogida y del capital social relacional que haya conseguido mantener en su país de origen (Schiff, 1998), que suelen ser mayor y menor, respectivamente, a medida que la residencia en el país de destino se va prolongando en el tiempo. En caso de los nuevos emigrantes españoles, al llevar relativamente poco tiempo residiendo en Chile, mantienen una gran parte de su 
capital social relacional en España (algo a lo que contribuyen las nuevas tecnologías de las telecomunicaciones, y en especial las videoconferencias, las redes sociales y los sistemas de mensajería instantánea -Facebook, Twitter, Skype, Whatsapp...-), consolidando con ello las nuevas familias transnacionales (Bryceson y Vuorela, 2002: 2), mientras que su capital relacional, al margen de la comunidad española, es relativamente pequeño. No obstante, la privatización de los servicios públicos y el elevado coste de vida que esto conlleva frenan, por el momento, las expectativas de muchos españoles de conformar una familia en Chile.

"Considero que Chile no es el lugar idóneo para formar una familia; el seguro médico y la educación resultan extremadamente caros" (mujer, 35 años).

La idea del retorno es la que tiene un mayor peso en las expectativas de futuro de los nuevos emigrantes españoles (44\% de los entrevistados); aunque en la mayoría de los casos el retorno solo se contempla cuando las condiciones laborales y sociales mejoren en España.

La consolidación de las redes sociales en el lugar de residencia, la obtención de permisos de residencia permanente, la adquisición de la nacionalidad del país de destino y la posibilidad de la reagrupación familiar reducen las aspiraciones de retorno de los emigrantes. A ello se suma en el caso de nueva emigración española a Chile las pocas esperanzas de los emigrantes de encontrar un empleo adecuado en España si deciden retornar, lo que lleva a algunos emigrantes españoles a asentarse definitivamente en Chile y no plantearse la idea del retorno (casi el 25\% de los entrevistados).

La consolidación de las redes sociales en el lugar de destino, el asociacionismo y el apoyo institucional demora el retorno y perpetúa la emigración. En este sentido, Chile cuenta con un gran número de asociaciones y centros de españoles que se reparten por casi todo el país, existiendo un gran número de ellas en ciudades en las que se concentra la emigración española; así nos encontramos con más de 20 asociaciones de españoles en Santiago (MESS, 2014); y muchos españoles han decido emprender negocios relacionados con la hostelería basados, sobre todo, en la comida española ("tabernas andaluzas"...) aprovechando esta oleada de emigrantes españoles, los cuales utilizan este tipo de negocios como lugar de encuentro.

Por otro lado, pese a las trabas que conlleva conseguir visados, los permisos de residencia temporal en Chile (visa temporaria, visa de residencia sujeta a contrato o visa de estudiante) otorgados a españoles ascendieron en 2013 a 4.918, mientras que los permisos de residencia permanente fueron 820 (Flores, 2014). Por lo que se refiere a la obtención de la nacionalidad chilena para los emigrantes españoles (doble nacionalidad), aún es pronto para poder valorar su incidencia, por cuanto que la Ley de Nacionalidad (Decreto Supremo 5.142, Art. 2) exige una residencia legal previa permanente de cinco años. $Y$ respecto del reagrupamiento familiar tampoco parece que sea problemático en Chile para los españoles, por cuanto el Reglamento de Extranjería (Decreto 597, Arts. 35 y 49) permite la obtención del visado de reagrupación a cónyuges e hijos del extranjero que tenga una visa temporaria o sujeta a contrato. No obstante, esta es una facilidad migratoria poco utilizada por los nuevos emigrantes españoles.

Para otro importante grupo de emigrantes españoles (más del 31\% de los entrevistados), la migración se consolida como un modelo de vida, conscientes de que su proceso de migración a Chile no termina con un retorno a España, sino que están sujetos a la demanda del mercado laboral global, que los moverá por diferentes partes del mundo, contribuyendo con ello a la reemigración global y permanente de trabajadores cualificados que no terminan de encontrar su "lugar en el mundo".

"Iré donde tenga trabajo; de esa manera ampliaré el currículum y, si las cosas mejoran en España, volveré con un currículum mejor... aunque lo dudo" (mujer, 25 años).

En general, algo menos de la mitad de los nuevos emigrantes españoles tienen la intención de retornar a España, siendo mayoría los que ya no se lo plantean junto con los que anteponen su vocación profesional al país de 
residencia. En el caso de los que desean retornar, solo lo harían si consideraran que han acumulado suficientes recursos económicos o experiencia profesional como para volver en unas condiciones de relativa tranquilidad y poder establecerse de nuevo en España, para quizá convertirse en unos "nuevos indianos".

Y aunque la mayoría contempla el proceso migratorio como una experiencia positiva, absorbiendo el aprendizaje de otras culturas, creciendo personal y profesionalmente, etc., suelen dejar constancia de su malestar e indignación por haber sido "expulsados" de España por la situación económica.

\section{Conclusiones}

Debido a la crisis que está padeciendo España desde 2008, miles de trabajadores españoles altamente cualificados están saliendo cada año del país en busca de mejores oportunidades. Y Chile, con el segundo gran ciclo expansivo de la minería chilena, se ha convertido en uno de los destinos preferentes de los emigrantes españoles a partir del 2011.

El perfil del nuevo emigrante español a Chile es el de una persona joven, mayoritariamente varón y de 25 a 34 años, que procede principalmente de Madrid, Andalucía y Cataluña y que reside en Santiago, Valparaíso o Coquimbo, que no está casado legalmente y que se encuentra altamente cualificado con estudios universitarios y de posgrado, en su mayoría de ingeniería.

Los nuevos emigrantes españoles llegan a Chile expulsados por la situación de crisis económica prolongada que padece España desde 2008 y atraídos por las oportunidades de empleo y de adquisición de experiencia profesional que ofrece este país. La mayoría llegan a Chile con la intención de buscar un empleo y solo una quinta parte llega con contrato de origen. También contribuyen a dicha migración la existencia de un sistema migratorio entre España y Chile basado en lazos familiares con otros españoles residentes en Chile, además de la existencia de una lengua y una cultura común.

Por otro lado, el conocimiento que tienen los españoles sobre Chile, fruto de haber sido uno de los destinos del turismo español durante los años de bonanza económica y del acceso que estos tienen a la información sobre el país por medio de las nuevas tecnologías de las telecomunicaciones y de las redes sociales, también han contribuido a dicha emigración.

Entre las dificultades iniciales que suelen encontrar los nuevos emigrantes españoles a su llegada a Chile se encuentra la regularización de la visa para poder trabajar y las trabas burocráticas con las que se encuentran (sobre todo para aquellos que no llegan con títulos universitarios homologados) y la necesidad de recurrir a la familia y los amigos para disponer de un capital mínimo con el que financiar el viaje y los primeros meses de estancia (sobre todo para aquellos que no llegan con contrato).

En general, los nuevos emigrantes españoles se encuentran satisfechos con su proceso migratorio a Chile y valoran especialmente la oportunidad que este país les brinda para ampliar su experiencia laboral, aunque sus niveles salariales son muy diversos, al igual que sus condiciones de trabajo y sus niveles de vida (en función de su titulación, del tipo de empresa nacional o transnacional para la que trabajen y del lugar de residencia). Aun así, en comparación con España, identifican como los principales problemas que padecen en Chile: la ineficiencia del sistema burocrático nacional; la calidad del sistema sanitario junto con la privatización de los servicios públicos y el encarecimiento de los mismos; las diferencias culturales; la precariedad de las condiciones laborales, sobre todo en trabajos no especializados; el acceso a la vivienda y los requisitos para poder realizar el contrato de alquiler; la inseguridad ligada a la brecha de desigualdad que se vive en Chile; y la contaminación, sobre todo en grandes ciudades.

Respecto de sus perspectivas de futuro son un poco más los nuevos emigrantes españoles que pretenden permanecer en Chile de forma indefinida y los que se plantean reemigrar a otros países, que los que sí consideran el retorno como una opción a medio plazo.

Así esta "tercera oleada de coños", cuya dimensión es aún difícil de precisar, aunque supone una pérdida de talento formado en 
España (brain drain), puede contribuir al desarrollo económico de Chile. Desde Chile se aprovecha la coyuntura económica de España y la alta cualificación española para, como hicieron en épocas anteriores, atraer inmigrantes cualificados que contribuyan al desarrollo económico del país. Parafraseando a Neruda vuelve a llegar a Chile "la sangre, la guitarra ciega, la frente perdida, los caídos, los héroes heridos..."

\section{Referencias bibliográficas}

ACOSTA, A. Extractivismo y neoextractivismo. Dos caras de la misma maldición. En: LANG, M. y MONKRANI, D. (editores). Más allá del desarrollo. Quito: Abya Yala, 2012, p. 83-118.

ADAMS, R. International Migration, Remittances, and the Brain Drain. A study of 24 labor-exporting countries. Nueva York: Banco Mundial, World Bank Policy Research Working Papers, 2003, No 3069.

ALAMINOS, A.; ALBERT, M.C. y SANTACREU, Ó. La movilidad social de los emigrantes españoles en Europa. Revista Española de Investigaciones Sociológicas, 2010, No 129, p. 13-35.

ALAMINOS, A. y SANTACREU, Ó. La emigración cualificada española en Francia y Alemania. Papers. Revista de Sociología, 2010, Vol. 95, No 1, p. 201-211.

ALCALDE, R.; PETROFF, A.; ALARCÓN, A. y CAVALCANTI, L. Una propuesta de estudio de las migraciones cualificadas contemporáneas desde España hacia los EE.UU. Madrid: Informes USA, Instituto Franklin - Universidad de Alcalá de Henares, 2013, Nº 1.

ALONSO, J.A. Migración internacional y desarrollo. Una revisión a la luz de la crisis. Nueva York: Naciones Unidas, CDP Background Paper, 2011, No 11.

ARANDA, D. Anuario ilustrado hispano chileno. Santiago de Chile: Selecta, 1929.

ARANGO, J. La explicación teórica de las migraciones: luz y sombra. Migración y Desarrollo, 2003, No 1, p. 1-30.
BALTAR, F. y GORJUP, M. T. Muestreo mixto online: Una aplicación en poblaciones ocultas. Intangible Capital, 2012, Vol.8, № 1, p. 123-149.

BARHAM, B. \& BOUCHER, S. Migration, Remittances, and Inequality: Estimating the Net Effects of Migration on Income Distribution. Journal of Development Economics, 1998, Vol. 55, p. 307-331.

BARRENO, J. Chile, país de las oportunidades. El Mundo. Edición América, 16/12/2012. Disponible en Internet: http:// www.elmundo.es/america/2012/12/15/noti cias/1355540156.html

BANCO CENTRAL DE CHILE (BCC). Compare su salario con el promedio mundial. BBC Mundo, 12/04/2012. Disponible en Internet: http://www.bbc.co.uk/mundo/noticias/2012/04/120404_calculador_sueldo_pro medio_mensual.shtml

BANCO CENTRAL DE CHILE (BCC). Informe de Política Monetaria. Marzo 2013. Santiago de Chile: Banco Central de Chile, 2013.

BENGOA, J. Conquista y barbarie. Ensayo crítico acerca de la conquista de Chile. Santiago de Chile: Sur, 1992.

BOVER, O. \& VELILLA, P. Migration in Spain: Historical Background and Current Trends. Bonn: Forschungsinstitutzur Zukun$\mathrm{ft}$ der Arbeit, IZA Discission Papers, $N^{\circ}$ 88, 1999.

BRAZIER, M. (editor). Global Mobility Survey Report 2012. Exploring the Changing $\mathrm{Na}$ ture of International Mobility. Santa Fe: Santa Fe Group, 2012.

BRICKMAN-BHUTTA, C. Not by the book: Facebook as sampling frame. Sociological Methods \& Research, 2012, Vol. 41, № 1, p. 57-88.

BRU, R. Viaje en el Winnipeg de la Familia Bru. Revista Universitaria de Pontificia Universidad Católica de Chile, 1989, № 27, p. 20-21.

BRYCESON, D. \& VUORELA, U. (editors). The Transnational Family. New European Frontiers and Global Networks. Oxford: Berg, 2002. 
CÁMARA HISPANO-CHILENA DE COMERCIO (CHC). Chile destaca a España como principal inversor en el país. Santiago de Chile: Cámara Hispano-Chilena de Comercio, Industria, Cultura, Deportes y Turismo, 2014. Disponible en Internet: http://www.cama rahispanochilena.net/Chile-destaca-a-Espanacomo-principal-inversor-en-el-pais_a525.html

CANO, M.V.; SOFFIA, M. y MARTÍNEZPIZARRO, J. Conocer para legislar y hacer política: los desafíos de Chile ante un nuevo escenario migratorio. Santiago de Chile: Centro Latinoamericano y Caribeño de Demografía (CELADE) - División de Población de la CEPAL, 2009.

COMISIÓN ECONÓMICA PARA AMÉRICA LATINA Y EL CARIBE (CEPAL). Estudio Económico de América Latina y el Caribe. Desafíos para la sostenibilidad del crecimiento en un nuevo contexto externo. Santiago de Chile: Comisión Económica para América Latina y el Caribe, 2014.

COMISIÓN EUROPEA. European Economic Forecast - Spring 2014. Bruselas: Comisión Europea, 2014.

DE CASTRO, R. En las orillas del Sar. Madrid: Cátedra, 2006 [1884].

DE LLERA, L. Algunos lugares comunes del último exilio español: 1936-1939. RILCE. Revista de Filología Hispánica, 1999, Vol. 15, $\mathrm{N}^{\circ} 1$, p. 75-91.

Decreto Supremo 5.142 de 1960. Fija el texto refundido de las disposiciones sobre nacionalización de extranjeros. Diario Oficial de la República de Chile. Santiago, 29 de octubre de 1960 (Modificado por la Ley 20.050).

Decreto Supremo 597 de 1984. Aprueba el nuevo reglamento de extranjería. Diario Oficial de la República de Chile. Santiago, 29 de noviembre de 1984. (Modificado por el Decreto Supremo 2.910).

DIRECCIÓN DE TRABAJO. Código de Trabajo. Santiago de Chile: Dirección de Trabajo del Gobierno de Chile, 2014.

DIXON, D.; MURRAY, J. \& GELATT, J. America's Emigrants: US Retirement Migration to Mexico and Panama. Washington: Migration Policy Institute, 2006.

DOCQUIER, F. \& LODIGIANI, E. SkiIled migration and business networks. Open Economies Review, 2010, Vol. 21, № 4, p. 565-588.

DURAND, J. Ensayo teórico sobre la migración de retorno. El principio del rendimiento decreciente. Cuadernos Geofiguras, 2004, No 35, p. 103-116.

EFE ECONOMÍA. Empresas españolas buscan negocios en el sector minero de América Latina en Expomin. El País 23/04/2014.

Disponible en Internet:

h t t p :// e conomia.elpais. com/e conomia/2014/04/23/ agencias/1398206114_584233.html

ELLERMAN, D. Policy Research on Migration and Development. Washington: Banco Mundial, World Bank Policy Research Papers, 2003, No 3117.

ESTRADA, B. Desarrollo empresarial urbano e inmigración europea: españoles en Valparaíso, 1880-1940. Madrid: Tesis Doctoral, Universidad Complutense de Madrid, 2012.

ESTRADA, B. República y exilio español en el fin del mundo. Revista de Indias, 2009, vol. LXIX, N² 245, p. 95-122.

FLORES, R. Caracterización de la migración en Chile: Una mirada desde instrumentos gubernamentales. Presentación del Seminario Migración y Derechos Humanos. Santiago de Chile: FLACSO, 2014. Disponible en Internet: http://www.flacsochile.org/wpcontent/uploads/2014/05/Seminario-flacso20-de-mayo-2014.ppt

GONZÁLEZ-ENRÍQUEZ, C. ¿Emigran los españoles? ARI 39/2013. Madrid: Real Instituto Elcano, 2013. Disponible en Internet:

http://www.realinstitutoelcano.org/wps/ portal/rielcano/contenido?WCM_GLOBAL_ CONTEXT=/elcano/elcano_es/zonas_es/ari392013-gonzalez-enriquez-emigran-los-espa noles

GONZÁLEZ-ENRÍQUEZ, C. La emigración desde España, una migración de retorno. ARI 
4/2012. Madrid: Real Instituto Elcano, 2012. Disponible en Internet:

http://www.realinstitutoelcano.org/wps/ portal/rielcano/contenido?WCM_GLOBAL_ CONTEXT=/elcano/elcano_es/zonas_es/ $\operatorname{ari} 42012$

GONZÁLEZ-FERRER, A. La nueva migración española. Lo que sabemos y lo que no. Zoom Político. Madrid: Fundación Alternativas, $2013 N^{\circ} 18$. Disponible en Internet:

http://www.falternativas.org/laboratorio/ libros-e-informes/zoom-politico/la-nuevaemigracion-espanola-lo-que-sabemos-y-loque-no

GUASCH, M.V. Reconstrucción identitaria en el exilio político: los refugiados de la guerra civil española en Chile. Santiago de Chile: Tesis Doctoral, Universidad Academia de Humanismo Cristiano, 2011.

HARRIS, J. \& TODARO, M. Migration, Unemployment and Development: A TwoSector Analysis. American Economy Review, 1970, Vol. 60, No 1, p. 126-142.

HERNÁNDEZ-SAMPIERI, R.; FERNÁNDEZ-COLLADO, C. y BAPTISTA-LUCIO, P. Metodología de la investigación. México: McGraw Hill, 2006.

HIDALGO-CAPITÁN, A.L. e IGLESIAS, J. La dimensión laboral del sistema económico mundial. En: HIDALGO-CAPITÁN, A.L. (coordinador). Economía Política Global. Globalización, gobernanza y crisis. Saarbrücken: Editorial Académica Española, 2011.

HIDALGO-CAPITÁN, A.L. Las migraciones internacionales en el contexto de la globalización. Una explicación multicausal. En: ROMERO-VALIENTE, J.M.; HIDALGO CAPITÁN, A.L.; MEDEIROS DE MENEZES, L.; SARMIENTO DA SILVA, E. Y SANTOS DE MATOS. M.I. (editores). Migraciones Iberoamericanas. Las migraciones España - Brasil. Huelva: Centro de Investigación en Migraciones - Universidad de Huelva, 2013, p. 235-258.

HIRSCHMAN, A. Salida, voz y lealtad. México: Fondo de Cultura Económica, 1977.

INSTITUTO DE COMERCIO EXTERIOR (ICEX). Empresas españolas establecidas en
Chile. Madrid: Instituto de Comercio Exterior, 2014.

INSTITUTO NACIONAL DE ESTADÍSTICA (INE). Censo de Población y Vivienda 2012. Santiago de Chile: Instituto Nacional de Estadísticas, 2013. Estuvo disponible en Internet: http://www.censo.cl/

INSTITUTO NACIONAL DE ESTADÍSTICA (INE). Encuesta Nacional de Empleo. Santiago de Chile: Instituto Nacional de Estadísticas, 2014. Disponible en Internet:

http://www.ine.cl/canales/chile_estadisti co/mercado_del_trabajo/nene/cifras_trimes trales.php.

INSTITUTO NACIONAL DE ESTADÍSTICA (INE). Nueva Encuesta Suplementaria de Ingresos. Santiago de Chile: Instituto Nacional de Estadísticas, 2012. Disponible en Internet:

http://www.ine.cl/canales/chile_estadisti co/mercado_del_trabajo/nene/nesi/archivos/ resultados_2012/enfoque_nesi2012.pdf

INSTITUTO NACIONAL DE ESTADÍSTICA (INE). Encuesta Anual de Estructura Salarial. Madrid: Instituto Nacional de Estadísticas, 2012. Disponible en Internet:

http://www.ine.es/jaxi/menu. d o ? t y p e = p c a x i s \& pat h = / t $22 /$ p133\&file $=$ inebase $\& \mathrm{~L}=0$

INSTITUTO NACIONAL DE ESTADÍSTICA (INE). Encuesta de Población Activa. Madrid: Instituto Nacional de Estadística, 2014a. Disponible en Internet:

http://www.ine.es/jaxi/menu.do;jsessio nid=0FF3 7F2E2E30EAE777A228D958812 0EB.jaxi01? type $=$ pcaxis $\&$ path $=/$ t2 2/e308_ mnu\&file $=$ inebase $\& N=\& L=0$

INSTITUTO NACIONAL DE ESTADÍSTICA (INE). Estadística de Migraciones. Madrid: Instituto Nacional de Estadística, 2014b. Disponible en Internet:

http://www.ine.es/jaxi/menu.do?type $=p$ caxis \&path $=\% 2 \mathrm{Ft} 20 \% 2 \mathrm{Fp} 277 \&$ file $=$ inebase $\& L=0$

INSTITUTO NACIONAL DE ESTADÍSTICA (INE). Estadística de Variaciones Residenciales. Madrid: Instituto Nacional de Estadística, 2014c. Disponible en Internet: 
http://www.ine.es/jaxi/menu.do?type $=p$ caxis \&path $=\% 2 \mathrm{Ft} 20 \% 2 \mathrm{Fp} 307 \&$ file $=$ inebase $\& \mathrm{~L}=0$

INSTITUTO NACIONAL DE ESTADÍSTICA (INE). Padrón de Españoles Residentes en el Extranjero. Madrid: Instituto Nacional de Estadística, 2014d. Disponible en Internet:

http://www.ine.es/jaxi/menu.do?L=0\&typ e $=$ pcaxis \&path $=\% 2 F t 20 \% 2 F p 85001 \&$ file $=$ in ebase

INSTITUTO NACIONAL DE ESTADÍSTICA (INE). Padrón Municipal, Madrid: Instituto Nacional de Estadística, 2014e. Disponible en Internet:

http://www.ine.es/jaxi/menu. $\mathrm{d}$ o ? t y $\mathrm{pe}=\mathrm{pc}$ c $\mathrm{xis} \& \mathrm{pat} \mathrm{h}=/ \mathrm{t} 20 /$ e245/\&file=inebase

INNOVUM. Fuerza laboral en la gran minería chilena. Diagnóstico y recomendaciones, 2011-2020. Santiago de Chile: Fundación Chile, 2011.

LA SEGUNDA. Minería requiere récord de personal, pero focalizado en funciones claves. La Segunda, 12/04/2013, p. 48-49.

LACZKO, F. \& BRIAN, T. North-South Migration: A Different Look at the Migration and Development Debate. International Organization for Migration, Technical Report, International Organization for Migration, 2013.

LEMUS, E. Identidad e identidades nacionales en los republicanos españoles en Chile. Ayer, 2002, № 47, p. 155-184.

LEMUS, E. La investigación de los refugiados españoles en Chile: fuentes y hallazgos en un exilio de larga duración. En: CERIC/ CERMI/Université Paris (editor). Exils et migrations ibériques vers l'Amerique Latine. París: Université de Paris VII, 1998, p. 273-293.

LI, X. \& McHALE, J. Emigrants and Institutions. Irlanda: NUI Galway Working Papers, Galway, National University of Irland, 2009. Disponible en Internet:

http://siteresources.worldbank. org/INTTRADERESEARCH/R esources/544824-1323963330969/83221971323963868323/Li_McHale.pdf.
MARPSATA, M. \& RAZAFINDRATSIMAB, N. Survey Methods for Hard-to-Reach Populations: Introduction to the Special Issue. Methodological Innovations Online, 2010, Vol.5, $\mathrm{N}^{\circ} 2$, p. 3-16.

MASANET, E. La migración cualificada de los profesionales de la salud en Portugal y España: una aproximación general. OBETS. Revista de Ciencias Sociales, 2010, Vol. 5, No 2, p. 243-267.

MASSEY, D.; ARANGO, J.; HUGO, G.; KOUAOUCI, A.; PELLEGRINO, A. \& TAYLOR, E. An Evaluation of International Migration: The North American Case. Population and Development Review, 1994, Vol. 75, № 4, p. 699-751.

MASSEY, D.; ARANGO, J.; HUGO, G.; KOUAOUCI, A.; PELLEGRINO, A. \& TAYLOR, E. Worlds in Motion. Understanding International Migration at the End of the Millennium. Oxford: Oxford University Press, 2005.

MATTOO, A. \& SUBRAMANIAN, A. CrissCrossing Migration. Policy Research Working Paper $\mathrm{N}^{\circ}$ 6539, 2013.

MENCOS, E. y BOJSTAD, A. Indianos: la gran aventura. Madrid: Antonio Machado Libros, 2004 [1998].

MENDOZA, C. y ORTIZ, A. Hacer las Américas. Migrantes españoles de alta calificación en la ciudad de México. Documents d'Anàlisis Geogràfica, 2006, Nº 47, p. 93-114.

MENDOZA, C. \& ORTIZ, A. Spanish Professionals in Mexico City: Narratives on Work and Labour Markets. Migration and Ethnic Themes, 2008, Vol. 24, No 4, p. 323-340.

MERCER. Estudio sobre el coste de la vida 2014. Nueva York: Marsh \& McLennan Companies, 2014.

MINISTERIO DE EMPLEO Y SEGURIDAD SOCIAL (MESS). La ciudadanía española en Chile. Datos Sociológicos de la ciudadanía española. Madrid: Ministerio de Empleo y Seguridad Social, 2014. Disponible en Internet:

http://www.empleo.gob.es/es/mundo/ consejerias/chile/emigracion/contenidos/da tossoc.htm 
MORGAN, T. Spaniards in the UK. A Successful Female Post-Industrial Migration. In: RYAN, L. \& WEBSTER, W. (editors). Gendering Migration: Masculinity, Femininity and Ethnicity in Post-War Britain. Lancashire: University of Central Lancashire, 2008, p. 137-154.

NAVARRO, C. y ESTRADA, B. Migración y redes de poder en América: el caso de los industriales españoles en Valparaíso (Chile), 1860-1930. Revista Complutense de Historia de América, 2005, Vol. 21, p. 115-146.

NERUDA, P. Himno y regreso. En: NERUDA, P. Himno y regreso. Santiago de Chile: Cruz del Sur, 1948 (1939).

ORGANIZACIÓN INTERNACIONAL PARA LAS MIGRACIONES (OIM). Informe sobre las migraciones internacionales 2013. El bienestar de los emigrantes y el desarrollo. Ginebra: Organización Internacional para las Migraciones, 2013.

ORGANIZACIÓN PARA LA COOPERACIÓN EL DESARROLLO ECONÓMICO (OCDE). Gross Domestic Product. París: Organización para la Cooperación el Desarrollo Económico, 2014

ORGANIZACIÓN PARA LA COOPERACIÓN EL DESARROLLO ECONÓMICO (OCDE). Panorama de la sociedad 2014. Indicadores sociales de OCDE. París: Organización para la Cooperación el Desarrollo Económico, 2014.

PIORE, M. Birds of Passage: Migrant Labour in Industrial Societies. Cambridge: Cambridge University Press, 1979.

PROGRAMA DE LAS NACIONES UNIDAS PARA EL DESARROLLO (PNUD). Informe sobre desarrollo humano 2009. Superando barreras: movilidad y desarrollo humano. Nueva York: Programa de las Naciones Unidas para el Desarrollo, 2009.

PROGRAMA DE LAS NACIONES UNIDAS PARA EL DESARROLLO (PNUD). Informe sobre Desarrollo Humano 2013. El ascenso del Sur. Progreso humano en un mundo diverso. Nueva York: Programa de las Naciones Unidas para el Desarrollo, 2013.
REAL ACADEMIA ESPAÑOLA (RAE). Diccionario de la Lengua Española. Madrid: Real Academia Española, 2014.

RODRÍGUEZ-FARIÑAS, M.J.; ROMEROVALIENTE, J.M. e HIDALGO-CAPITÁN, A.L. Los exiliados económicos. La nueva emigración española a México (2008-2014). Scipta Nova, Revista Electrónica de Geografía y Ciencias Sociales, 2015 (aceptado para su publicación).

ROMERO-VALIENTE, J.M. La migración española a Brasil (fines siglo XIX - actualidad): magnitudes y evolución. En: ROMEROVALIENTE, J.M.; HIDALGO CAPITÁN, A.L.; MEDEIROS DE MENEZES, L.; SARMIENTO DA SILVA, E. Y SANTOS DE MATOS, M.I. (editores). Migraciones Iberoamericanas. Las migraciones España - Brasil. Huelva: Centro de Investigación en Migraciones - Universidad de Huelva, 2013, p. 33-58.

ROMERO-VALIENTE, J.M. La movilidad exterior de los españoles y las españolas en la actualidad. Huelva: Informe inédito elaborado para la Dirección General de Migraciones del Gobierno de España, Fundación Universidad de Huelva, 2012.

SASSEN, S. Globalization and its Discontents. Essays on the New Mobility of People and Money. Nueva York: New Press, 1998.

SCHIFF, M. Trade, Migration and Welfare: The Impact of the Social Capital. Washington: Banco Mundial, 1998.

VÁZQUEZ, V. y AMORES, J.B. La emigración de navarros y vascongados al nuevo mundo y su repercusión en las comunidades de origen. En: ERIAS, A. (editor). La emigración española a Ultramar, 1492-1914. Madrid: Tabapress, 1991.

VILLARINO, J. Mensaje del Presidente Ejecutivo. En: CONSEJO MINERO (editor). Reporte Anual Consejo Minero 2012-2013. Santiago de Chile: Consejo Minero, 2013.

ZAMORA, I. La Universidad de Chile busca Doctores que hablen español por $3.500 €$ al mes. $A B C, 2012$. Disponible en Internet: http://www.abc.es/20120621/ sociedad/abci-chile-trabajadores-espanol-21/06/201206210740.html 
